\title{
Cytological organization of the alpha component of the anterior olfactory nucleus and olfactory limbus
}

\author{
Jorge Larriva-Sahd* \\ Instituto de Neurobiología, Universidad Nacional Autónoma de México, Querétaro, México
}

\section{Edited by:}

Micheal Baum, Boston University, USA

\section{Reviewed by:}

Alino Martinez-Marcos, Universidad de Castilla, Spain

Daniel W. Wesson, Case Western

Reserve University, USA

*Correspondence:

Jorge Larriva-Sahd, Instituto de

Neurobiología, Universidad Nacional

Autónoma de México, Boulevard

Juriquilla 3002, Querétaro,

CP 76230, México.

e-mail: jlsneuro@unam.mx
This study describes the microscopic organization of a wedge-shaped area at the intersection of the main (MOB) and accessory olfactory bulbs (AOBs), or olfactory limbus $(\mathrm{OL})$, and an additional component of the anterior olfactory nucleus or alpha AON that lies underneath of the AOB. The OL consists of a modified bulbar cortex bounded anteriorly by the MOB and posteriorly by the AOB. In Nissl-stained specimens the OL differs from the MOB by a progressive, antero-posterior decrease in thickness or absence of the external plexiform, mitral/tufted cell, and granule cell layers. On cytoarchitectual grounds the $\mathrm{OL}$ is divided from rostral to caudal into three distinct components: a stripe of glomerular-free cortex or preolfactory area (PA), a second or necklace glomerular area, and a wedge-shaped or interstitial area (INA) crowned by the so-called modified glomeruli that appear to belong to the anterior $\mathrm{AOB}$. The strategic location and interactions with the main and AOBs, together with the previously noted functional and connectional evidence, suggest that the OL may be related to both sensory modalities. The alpha component of the anterior olfactory nucleus, a slender cellular cluster (i.e., $650 \times 150 \mu \mathrm{m}$ ) paralleling the base of the $A O B$, contains two neuron types: a pyramidal-like neuron and an interneuron. Dendrites of pyramidal-like cells (P-L) organize into a single bundle that ascends avoiding the $\mathrm{AOB}$ to resolve in a trigone bounded by the edge of the $\mathrm{OL}$, the $\mathrm{AOB}$ and the dorsal part of the anterior olfactory nucleus. Utrastructurally, the neuropil of the alpha component contains three types of synaptic terminals; one of them immunoreactive to the enzyme glutamate decarboxylase, isoform 67.

Keywords: olfactory limbus, interstitial neurons, anterior olfactory nucleus, cytology

\section{INTRODUCTION}

While the cytological organization of the rodent main and accessory olfactory bulbs (AOB) has been depicted and most of its constituent neurons are known, growing evidence suggests that the structural and functional differentiation of the bulbar cortex is not homogeneous. In fact, both the main (MOB) and AOBs possess distinct neurons embedded in a neuropil that yields the characteristic laminated appearance when studied with both silver and aniline stains (Macrides and Davis, 1983). Neurons in the MOB are distributed into two structural domains: a stratified cortex and a medulla or core. Periglomerular or juxtaglomerular superficial short axon neurons, external tufted, satellite, and von Gehughten cells are primarily found in the external granule and external plexiform (EPL) layers. A distinct row of mitral cells underscores the EPL. Below the mitral cell layer, there is a cell-poor stratum or internal plexiform area bounding the deeper granule cell layer that arbors the homonymous cells and

\footnotetext{
Abbreviations: aAON, anterior olfactory nucleus, alpha component; $\mathrm{AOB}$ Accessory olfactory bulb; EPL, external plexiform layer; GAD67, enzyme glutamic acid decarboxylase, isoform 67; GAD-i, immunoreactivity to the enzyme glutamic acid decarboxylase, isoform 67; INA, interstitial area of the olfactory limbus; INBi, Interstitial neuron bulbi, interneuron; INBp, Interstitial neuron bulbi, projecting cell; LOT, lateral olfactory tract; MOB, Main olfactory bulb; NG, necklace glomerulus; NGA, Olfactory limbus, area of the necklace glomeruli; OL, olfactory limbus; PA, Preolfactory area of the olfactory limbus; P-L, pyramidal-like cell.
}

scattered local circuit neurons, namely, Blanes, Cajal, and Golgi neurons (Valverde, 1965, see Kosaka and Kosaka, 2011). Neurons having structural and immunohistochemical features of interneurons may send collaterals to supragranular layers in the main and accessory (Larriva-Sahd, 2008) olfactory bulbs, or even send projecting fibers beyond the confines of the MOB (Kosaka and Kosaka, 2007; Eyre et al., 2008).

The bulbar medulla, pierced by a rostral extension of the lateral ventricle that in laboratory rodents obliterates after birth, contains clustered epithelial ependymal cells, and cell progentiors in various stages of differentiation (Doetsch et al., 1997) to granule and periglomerular cells (Lledo et al., 2008). An additional set of neurons, has been recently described in association with to the rostral migratory stream, the so-called "medullary neurons" (Paredes and Larriva-Sahd, 2010).

Although most neuron types found in the AOB mimic those encountered in the $\mathrm{MOB}$, striking regional differences in their overall organization have been detected (see Larriva-Sahd, 2008). Indeed, structural and physiological evidence suggests that the transition between the MOB and $\mathrm{AOB}$ is not sharp. A distinct set of glomeruli outlining those in the posterior aspect of the $\mathrm{MOB}$, and the foremost of the AOB, have been described. These glomeruli that have been referred to as the glomerular necklace (NG) (Shinoda et al., 1989), exhibit striking physiological (see Stowers and Logan, 2010) and, connectional (Ring et al., 1997; 
Fuss et al., 2005) differences, from those in the rest of the bulbar cortex. Unlike olfactory glomeruli that are known to be responsive for volatile substances interacting with nasal olfactory receptors, modified glomeruli are selectively activated by a nipple-associated pheromone (Greer et al., 1982). Further, connectional evidence has defined that those glomeruli adjacent to the AOB represent a unique subset of the NG (Fuss et al., 2005) as they receive axons from the ganglion discovered by Grueneberg (1973) in the nasal vestibule. Interestingly, expression of mRNA's encoding neuromodulators (i.e., CCK and VIP) and hypothalamic releasing hormones (TRH and CRH) (Senba et al., 1990), is higher in both glomeruli and neuropil at the MOB-AOB boundary with respect to both the $\mathrm{MOB}$ and $\mathrm{AOB}$ themselves. Lastly, are the so-called interstitial neurons of the bulbi (INBs) that represent another marked structural specialization in the oral interaction of the $\mathrm{AOB}$ with the MOB. In fact, INBs seem to be a unique neuron group whose pyramidal-like and short axon neurons stand out from the native neurons populating the adjacent $\mathrm{MOB}$ and AOB (Larriva-Sahd, 2008).

A third small neuron group lies between the base of the AOB and the bulbar core white matter. Santiago Ramón y Cajal (1904) discovered this cluster in aniline-stained sections defining that it was composed by large, polygonal neurons, hence, different from those observed in the rest of the bulbar cortex. Likewise, in the 1960s Lohman (1963), studying the AON in Nissl-stained sections incorporated this nucleus to the "pars rostralis of the anterior olfactory nucleus." Similarly, Macrides and Davis (1983) endorsed this neuron group to the AON including it to the "dorsal sector of pars externa of the AON.” Then, Valverde et al. (1989) outlined the first Golgi description of the "cell group alpha of the nucleus olfactorius anterior" (aAON). Lastly, DeCarlos et al. (1989) studying the connectivity of the AON in the same species, found that the " $\alpha$ group" projects to the contralateral MOB.

As part of a series of ongoing studies aimed at depicting the neuronal organization of the rodent rhinencephalon (LarrivaSahd, 2008, 2010; Paredes and Larriva-Sahd, 2010), the present study was conducted to describe the cytological organization of the $\mathrm{aAON}$ and a complex region between the anterior aspect of the AOB and the caudal limit of the MOB. The study was primarily conducted in specimens from adult rats, although mouse and guinea-pig specimens from our collection were examined to define interspecies homology. The study combines silver, aniline, immunohistochemistry, and electron microscopic techniques.

\section{MATERIALS AND METHODS ANIMALS}

Male Sprague-Dawley rats killed at 10 weeks of age were used. The animals were kept at constant temperature $\left(24^{\circ} \mathrm{C}\right)$ and photoperiods ( $14 \mathrm{~h}$ light $-10 \mathrm{~h}$ dark), with free access to food and water. All experimental manipulations and sacrifices were made according to the ethical policies of animal care and handling of our institute.

\section{SILVER IMPREGNATIONS}

\section{Rapid golgi}

Due to the capriciousness of impregnation obtained with the rapid-Golgi technique, 330 adult rat brains were used from our archive (Larriva-Sahd, 2008, 2010). Additionally, one-hundred brains from age-matched adult CD3 mice $(n=90)$ (Paredes and Larriva-Sahd, 2010) and guinea pigs $(n=10)$ were included. Each animal was sacrificed by decapitation under deep anesthesia with pentobarbital ( $30 \mathrm{mg} / \mathrm{kg}$ ), and the brain was removed. Tissue blocks consisted of 3 to 4 -mm-thick brain samples trimmed in sagittal, coronal, or horizontal planes. Each tissue block was left for 15-20 days in an aqueous solution containing 3\% potassium dichromate and $0.25 \%$ osmium tetroxide and transferred to a $0.75 \%$ silver nitrate solution for the following 20 days. Then, each tissue block was held within an external shell of paraffin, and $150 \mu \mathrm{m}$-thick sections were cut on a sliding microtome. The sections were then left for $10 \mathrm{~min}$ in $70 \%$ ethyl alcohol, dehydrated in graded solutions of propyl alcohol-water, cleared in terpineol-xylene, mounted, and coverslipped with Entellan.

\section{Golgi-Cox-NissI}

Additional adult rat brains $(n=20)$ were obtained (vide supra) and stored for 15-20 weeks in a solution containing: $1 \%$ potassium dichromate, $0.8 \%$ potassium chromate, and $1 \%$ mercuric chloride dissolved in deionized water. Each brain was cut sagittally or coronally into $140 \mu \mathrm{m}$ sections in a sliding microtome. Next, the sections were mounted on slides and immersed in a solution of T-Max (Kodak) in deionized water (1:65) for $30 \mathrm{~min}$, following a 15-min fixation in rapid-fixer (Kodak) diluted 1:30 into water. Then, the slides were left for $15 \mathrm{~min}$ in deionized water and counterstained with the Nissl technique. Finally, sections were dehydrated in graded solutions of ethanol-water, cleared in terpineol-xylene, and coverslipped with resin.

\section{Nissl staining}

The cytoarchitecture of the olfactory bulb was studied in transverse and sagittal sections from the brains of five adult Wistar albino rats that were successively weighed, deeply anesthetized with pentobarbital $(300 \mathrm{mg} / 2.5 \mathrm{~kg})$, and perfused through the heart with $4 \%$ paraformaldehyde dissolved in phosphate buffer ( $\mathrm{PB}, 0.15 \mathrm{M}, \mathrm{pH} 7.4$ ). The brains were transferred to fresh fixative and left overnight at $4^{\circ} \mathrm{C}$. Then, each brain was cryoprotected with $40 \%$ sucrose dissolved in distilled water and cut at $40 \mu \mathrm{m}$ intervals. Then, the tissue samples were immersed for $20 \mathrm{~min}$ in a solution containing $0.1 \mathrm{gm}$ of cresyl-violet, $0.3 \mathrm{ml}$ glacial acetic acid dissolved in $100 \mathrm{ml}$ of distilled water. Following staining sections were dehydrated in graded etyl-alcohols, cleared in xylene and coverslipped with Entellan.

\section{Electron microscopy}

To determine the ultrastructural characteristics of the aAOB neurons and surrounding neuropil, the brains of six adult rats were processed as detailed elsewhere (Larriva-Sahd, 2004, 2006). In short, deeply anesthetized rats (vide supra) were perfused through the left ventricle with $250 \mathrm{ml}$ of $4 \%$ paraformaldehyde$2.5 \%$ glutaraldehyde in $0.15 \mathrm{M} \mathrm{PB}, \mathrm{pH}$ 7.3. Following dissection, the brain was immersed in additional fixative and stored overnight at $4^{\circ} \mathrm{C}$. After $24 \mathrm{~h}$, half to one millimeter sagittal slices through the olfactory bulb and its peduncle were obtained. Areas of interest were sampled under a dissecting microscope and postfixed for one $\mathrm{h}$ in $1 \%$ osmium tetroxide dissolved in the same buffer as the aldehydes, dehydrated, and flat embedded in epoxy 
resins. Half to one-micrometer-thin sections were obtained from the tissue blocks with a Leica ultramicrotome equipped with glass knives. The sections were stained with toluidine blue and coverslipped. From the surface of these trimmed blocks, ultrathin sections ranging from 80 to $90 \mathrm{~nm}$ were obtained with a diamond knife and mounted on 200-mesh copper grids. The sections were sequentially stained with aqueous solutions of uranium acetate and lead citrate and then studied in a JEOL 1010 electron microscope.

\section{Immunocytochemistry}

Three supplementary aldehyde-fixed rat brains were utilized for pre-embedding immunocytochemistry. Eighty-micron-thick sections were obtained with a vibratome, at room temperature. Sagittal sections containing the areas of interest were processed. Sections were collected in $0.1 \mathrm{M} \mathrm{PB}, \mathrm{pH} \mathrm{7.2,} \mathrm{and} \mathrm{preincu-}$ bated for $60 \mathrm{~min}$ in a $0.1 \mathrm{M}$ solution containing $0.1 \mathrm{M} \mathrm{PB}, 0.8 \%$ bovine serum albumin, $0.9 \%$ sodium chloride, $0.5 \%$ normal goat serum (NGS), and $2 \mathrm{mM}$ sodium azide. Then, sections were incubated overnight (i.e., $10 \mathrm{~h}$ ) with the rabbit polyclonal antiserum directed against GAD 67 (Chemicon, International). The primary antibody was diluted $1: 3000$ or $1: 2500$ in $0.1 \mathrm{M}$ TrisPB (TBP) with 3\% NGS. After rinsing in PB (three times for $10 \mathrm{~min}$ each), the sections were incubated for $1 \mathrm{~h}$ in the biotinylated secondary antibody that consisted of goat anti-rabbit IgG (Vector Laboratories, Burlingame, CA, USA) diluted to 1:500 in $0.1 \mathrm{M} \mathrm{PB}$ with $3 \%$ NGS. Sections were then incubated with the avidin-biotin-peroxidase conjugate (1:100 in $0.1 \mathrm{M} \mathrm{TPB}$; Vector Laboratories) for $40 \mathrm{~min}$, and rinsed sequentially in TPB and $0.05 \mathrm{M}$ Tris-HCl buffer, $\mathrm{pH}$ 7.6. For visualization of immunoreactive sites, sections were treated with $0.05 \% 3,3^{\prime}$-diaminobenzidine and $0.01 \%$ hydrogen peroxide for $5 \mathrm{~min}$. Lastly, sections were rinsed, and postfixed in osmium tetroxide and further processed for electron microscopic observations.

\section{DATA ANALYSIS}

\section{Light microscopy}

A total of 30 drawings from complete neurons were used to assess the structure and proportions of each cell type. Measurements from the two neuron types found at the "alpha anterior olfactory nucleus or cell group $\alpha$ " (aAON) according to Valverde et al. (1989) were obtained from digital reproductions of drawings with a personal computer aided by Kontron 400 software (Carl Zeiss). Size of the neuron somata was determined in toloudine-blue stained specimens that had been sectioned at one micrometer and included the aAON and the dorsal component of the anterior olfactory nucleus. A total of 100 neurons were photographed per animal $(n=5)$ and the somatic areas measured with the Kontron software. Areas were pooled per site and compared with the Students $t$-test.

Illustrations obtained by scanning representative drawings were framed, sized, and labeled with photoediting software (Adobe Photoshop 7). Photomontages from specimens were made from series of 4-25 images obtained at different focal depths with a digital camera (AxioCam MRc, Zeiss; Carl Zeiss, Germany). Then, areas in sharp focus were "cut" and merged down with the software. No modifications other than in color, contrast, size, and labeling were made of the original images.

\section{Electron microscopy}

To define the numerical densities of synapses, synaptic boutons, and axo-axonic (i.e., synapto-synaptic) terminals, specimens from five adult male rats were utilized. Numerical density of synaptic boutons included those showing pre-, and postsynaptic specializations and a florid granular content, allowing unambiguous identification (vide infra); terminals that were partially sectioned, or lacked an identifiable postsynaptic target were neglected.

\section{RESULTS}

Given the fact that the transition between the AOB with the MOB is not sharp (Larriva-Sahd, 2008), and since this territory has not previously been described, it is necessary to provide a general description of this frontier before dealing with the native cellular elements. Hence, the term olfactory limbus (OL) will be used to refer to it throughout this study. The use of this term is further justified by the fact that in adult rodents the cytological characteristics of the OL differ from those of the MOB and $\mathrm{AOB}$ as presented next.

\section{INTERACTION BETWEEN THE MAIN AND ACCESSORY OLFACTORY BULBS: THE OLFACTORY LIMBUS Olfactory limbus}

Naked eye or low magnification inspection of the dorsal surface of the rat olfactory bulb reveals an almond-shaped elevation that follows the anterior pole of the frontal lobe, lying dorsally (Figures 1,2A,3E,4). This eminence between the MOB and $\mathrm{AOB}$ encompasses a heterotypical bulbar cortex or OL. The most obvious characteristic of the $\mathrm{OL}$ is the variable extent of modification from the laminar pattern observed throughout the olfactory bulb. Laterally and medially (i.e., distal) to the $\mathrm{AOB}$, the $\mathrm{OL}$ is continuous with the caudal end of the MOB

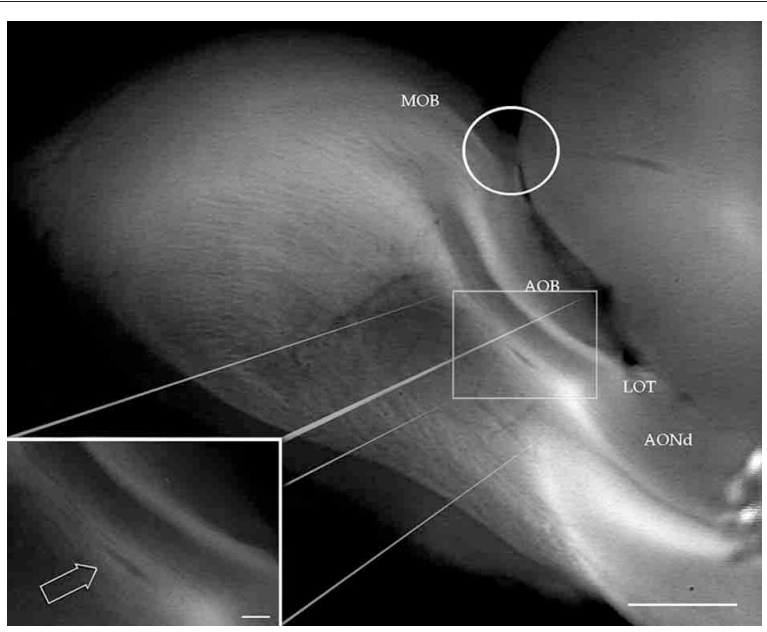

FIGURE 1 | Digital photograph from the dissecting microscope showing the rat olfactory bulb after a sagittal cut. At the junction of the main $(\mathrm{MOB})$ and accessory $(\mathrm{AOB})$ olfactory bulbs, the olfactory limbus (encircled) protrudes dorsally. LOT, lateral olfactory tract. AONd, dorsal component of the anterior olfactory nucleus. Inset: high magnification view of the alpha anterior olfactory nucleus (arrow) lying in the bulbar white matter, underneath the AOB. Scale bars: $0.4 \mathrm{~mm}$ in $\mathrm{A}, 150 \mu \mathrm{m}$ in insert. 


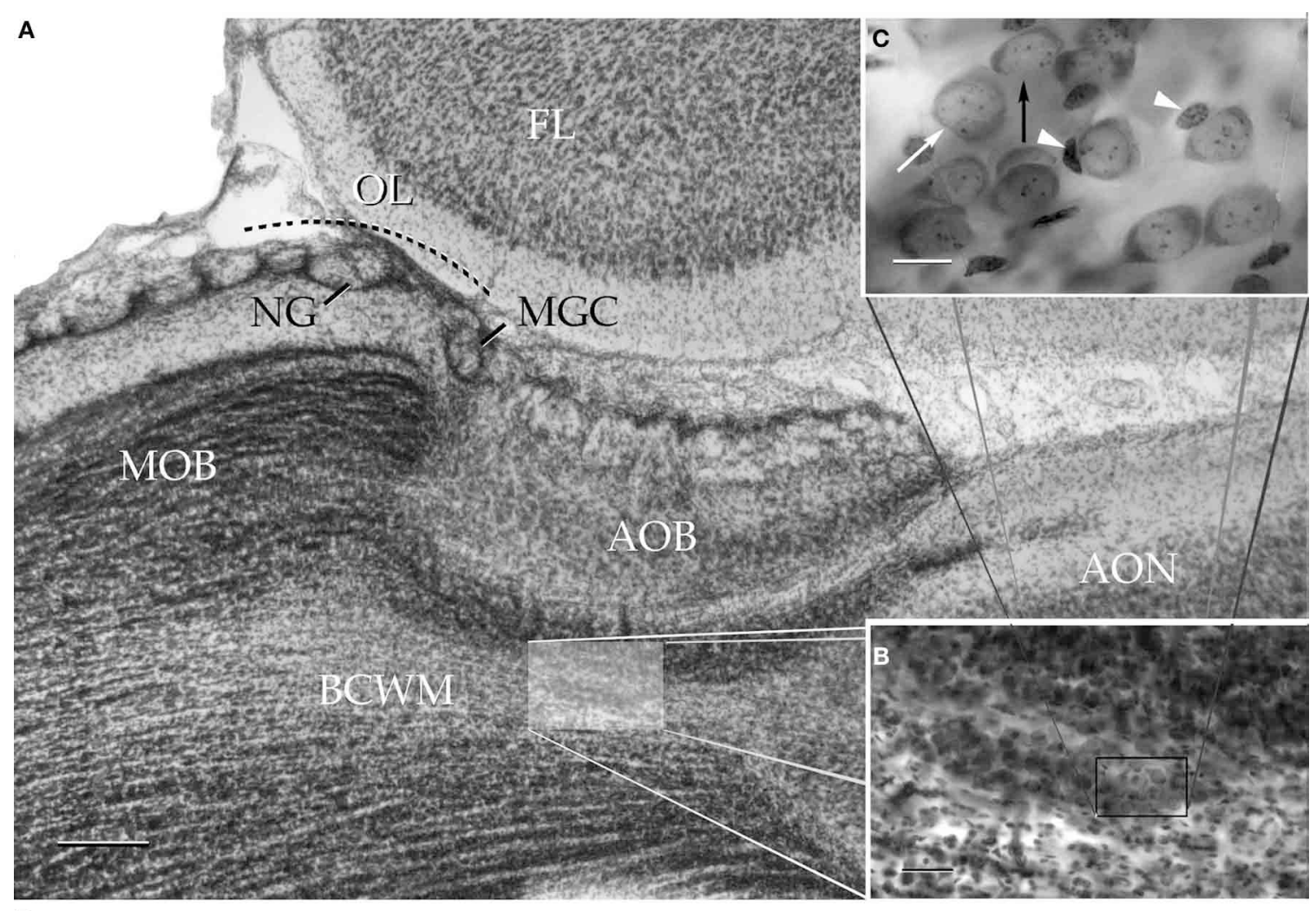

D

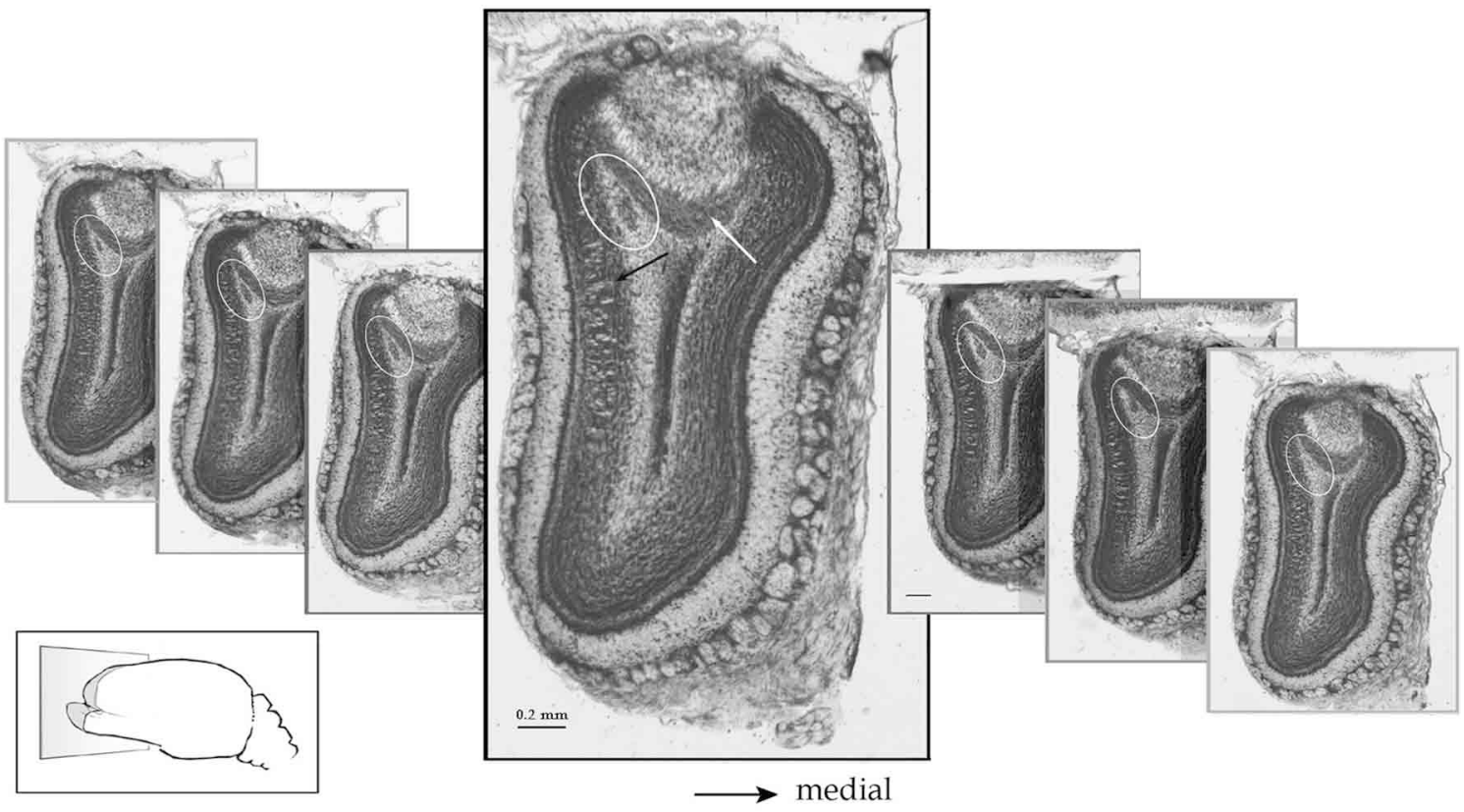

FIGURE 2 | Survey pictures of the olfactory bulb and the alpha component of the anterior olfactory nucleus as seen after thionine staining. (A) Sagittal section. The alpha component of the anterior olfactory nucleus (shaded) is embedded in the bulbar core white matter (BCWM) coursing horizontally, beneath the accessory olfactory bulb (AOB). FL, frontal lobe. (B) The spindle-shape alpha nucleus surrounded by the deep bulbar white matter is composed of dense packaged neurons. (C) High magnification micrograph from the alpha nucleus that is composed of polygonal (white arrow) and oblong, somewhat smaller, neurons (black arrow). The former neurons may exhibit an associated satellite cell (arrowheads). (D) Serial transverse sections from caudal (right) to rostral (left) showing the alpha component (encircled) in its rostrocaudal extent; note that the nucleus lies in a triangular area bounded by the granule cell (black arrow) and internal cellular (white arrow) layers of the main and accessory olfactory bulbs, respectively. Scale bars $=200 \mu \mathrm{m}$ in $\mathbf{A}$ and $\mathbf{D}, 50$ in $\mathbf{B}$, and 10 in $\mathbf{C}$. Nissl technique, adult rat brain. 

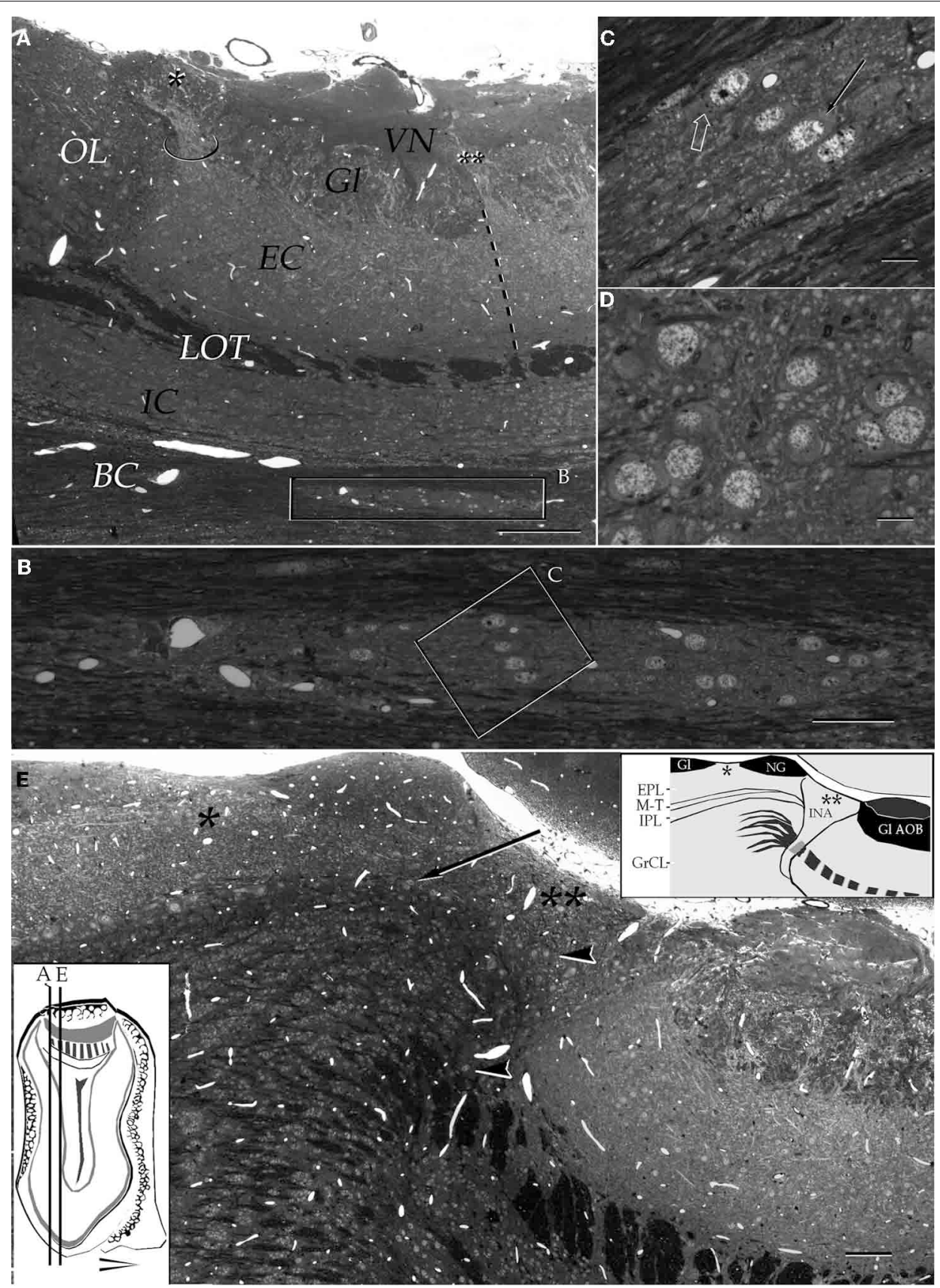

\section{FIGURE 3 | Light micrographs from plastic-embedded longitudinal} sections through the olfactory bulb. (A) Section at the caudal intersection of the main olfactory bulb with the accessory olfactory bulb (right side). Note the dendritic bundle (circle) arising from the external cellular layer (EC) and resolving at the base of a modified glomerulus (asterisk), adjacent to the olfactory limbus (OL). Beneath, embedded in the bulbar core white matter $(\mathrm{BC})$, lies the alpha component of the anterior olfactory nucleus (boxed). $\mathrm{VN}$ vomeronasal nerve layer; GI, glomerular layer; LOT, lateral olfactory tract; IC, internal cellular layer. At the glomerular-free area of the accessory olfactory bulb the linea alba (dashed) separates the external cellular layer in a rostral (left) and caudal halves. (B) Higher magnification of the alpha

component of the anterior olfactory nucleus. (C) Neuron somata from the alpha component of the anterior olfactory nucleus (boxed in B). A neurona cluster made up of medium-sized neurons (solid arrow) and a large neuron whose cytoplasm contains Nissl substance (hollow arrow). (D) Neuron somata in the dorsal part of the anterior olfactory nucleus at the same magnification as the micrograph shown in $\mathbf{C}$; note the difference in size and distribution of neurons in comparison to those from the alpha component shown in C. (E) Micrograph depicting the olfactory limbus between the main (left) and accessory olfactory bulbs. At the upper left is the caudal end of the main olfactory bulb, followed by the glomerular-free preolfactory (asterisk) area. The latter faces a second area or the necklace glomeruli whose external plexiform (EPL) and mitral/tufted cell (M-T) layers become indistinct and hypocellular (arrow), respectively. Following caudally is a wedge-shaped or interstitial area (double asterisik) (INA) that lacks laminar organization, having clusters of cells of assorted size (arrow-heads). GI-AOB, glomerular layer of the accessory olfactory bulb; IPL, internal plexiform layer; $\mathrm{GrCL}$ granule cell layer. Scale bars: $100 \mu \mathrm{m}$ in A, 40 in $\mathbf{B}$ and $\mathbf{E}$, and 10 in C and D. One-micrometer-thick sections, adult rat brain, toluidine blue staining. 


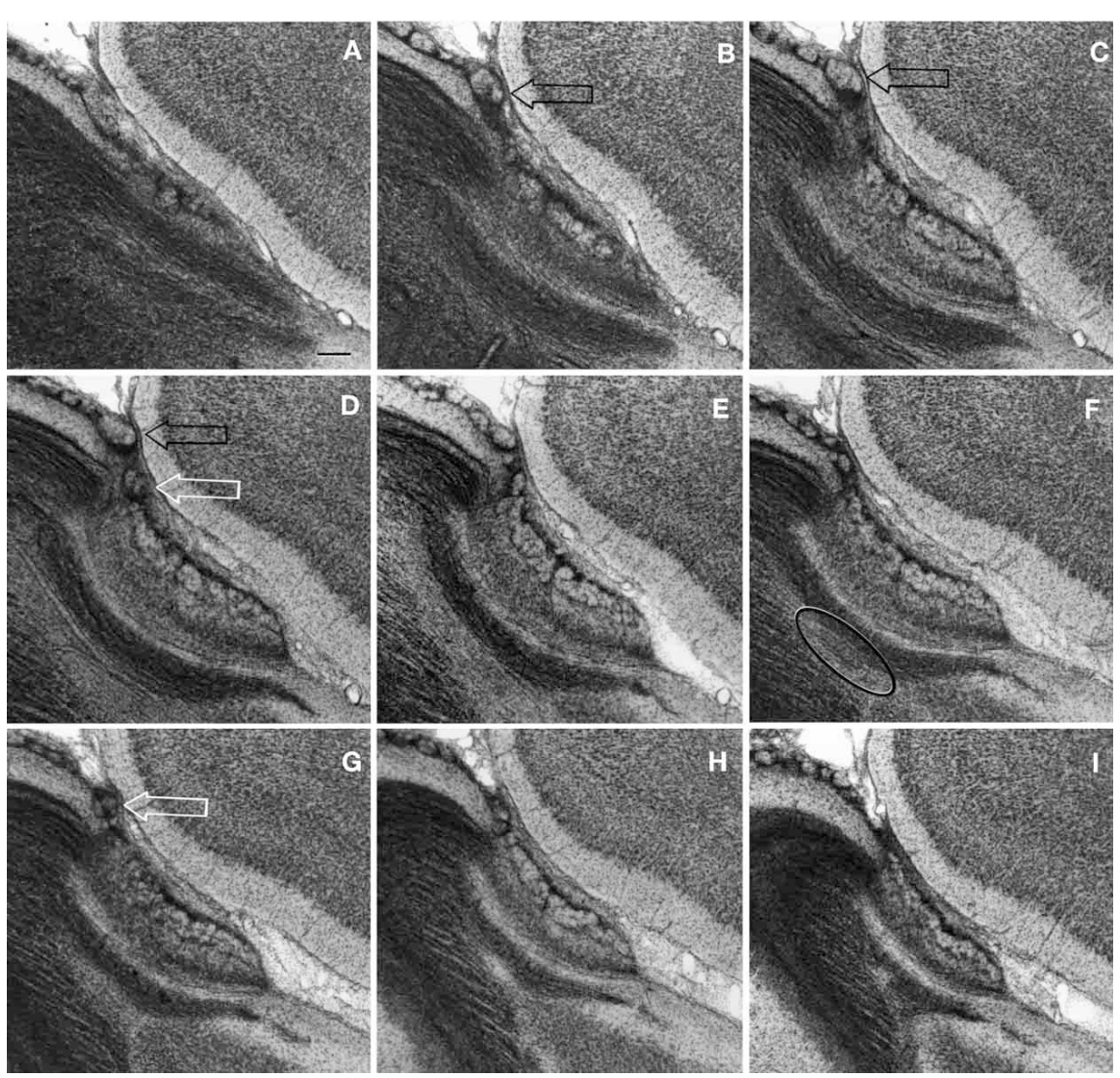

FIGURE 4 | Successive Nissl-stained sections from lateral (A) to medial (I) through the olfactory limbus. Note that glomeruli from the modified glomerular complex lie on the anterior part of the accessory olfactory bulb (white arrows) and those from the necklace (black arrows) crown the homonymous area of the olfactory limbus. Circle = alpha component of the anterior olfactory nucleus. Scale bar $=100 \mu \mathrm{m}$. Adult rat brain. that resolves in the cisura circularis (Lohman and Mentink, 1969).

\section{Parceling of the olfactory limbus}

According to the internal structure of the OL it can be divided into three areas. The foremost or preolfactory area (PA) consists of a modified main olfactory cortex having the following dissimilarities (Figure 3E): it lacks glomeruli, is thinner than the adjacent MOB cortex, and its row of mitral cells that, in the MOB underscores the mitral-tufted cell layer, contains fewer and smaller mitral cells. Concurrently, the PA exhibits a rudimentary external plexiform layer (EPL) that is more slender than that in the adjacent MOB. Lastly, the internal plexiform and granule cell layers are thinner than their MOB counterparts. Following caudally, is the second area of the necklace glomeruli (NGA), it is the most prominent due to one or two solitary glomeruli that bulge-up to the pial surface. In addition to location, necklace glomeruli (NG) stand out from those in the $\mathrm{MOB}$ and $\mathrm{AOB}$, in that they are bigger and hypercellular (Figures 4B-F). Still another, important difference of NGs in the OL from those located elsewhere is that they are united by cellular bridges that contain a fibrous core (Figure 5B) (see Shinoda et al., 1989). Underneath the NG, the region equivalent to the EPL reaches its minimum in terms of both thickness and cellularity and, like in the PA, it is discontinuous having fewer and smaller, mitral-and tufted-cells (Figures 3F,6). A third, or interstitial area (INA), consists of a relatively hypocellular, wedge-shaped area between the anterior aspect of the AOB and the caudal part of the NGA. Superficially the INA is somewhat lower than the adjacent NGA as it lacks glomeruli or, more commonly, exhibits two or three modified glomeruli similar to those seen in the new-born rodent and referred to as the modified glomerular complex (MGC) (Teicher et al., 1980). Sagittal sections through the oral part of the AOB reveal that these MGC arise from principal cell dendrites in the AOB. In fact these distal dendrites bend rostrally to overlie the posterior INA (Figures 2A,3A,4D). The deep part of the INA is triangular in shape with the apex proceeding ventrally to resolve in the deep bulbar white matter (Figures 3E,4,5B). While the posterior aspect of the INA faces the $\mathrm{AOB}$, its lower third is pierced by the convergent fibers of the lateral olfactory tract (LOT) on their way to the AOB (see Figures 25,26A in Larriva-Sahd, 2008). The INA stands out from the former two areas, and from the entire olfactory bulb in that is devoid of a laminar organization (Figures 2,3,4,5). Concurrently, several peculiarities differentiate the IN from the surrounding structures. The first is that neurons therein (vide infra) form small cellular clusters. Second, it lacks a granule cell layer. Furthermore, the LOT that in the 

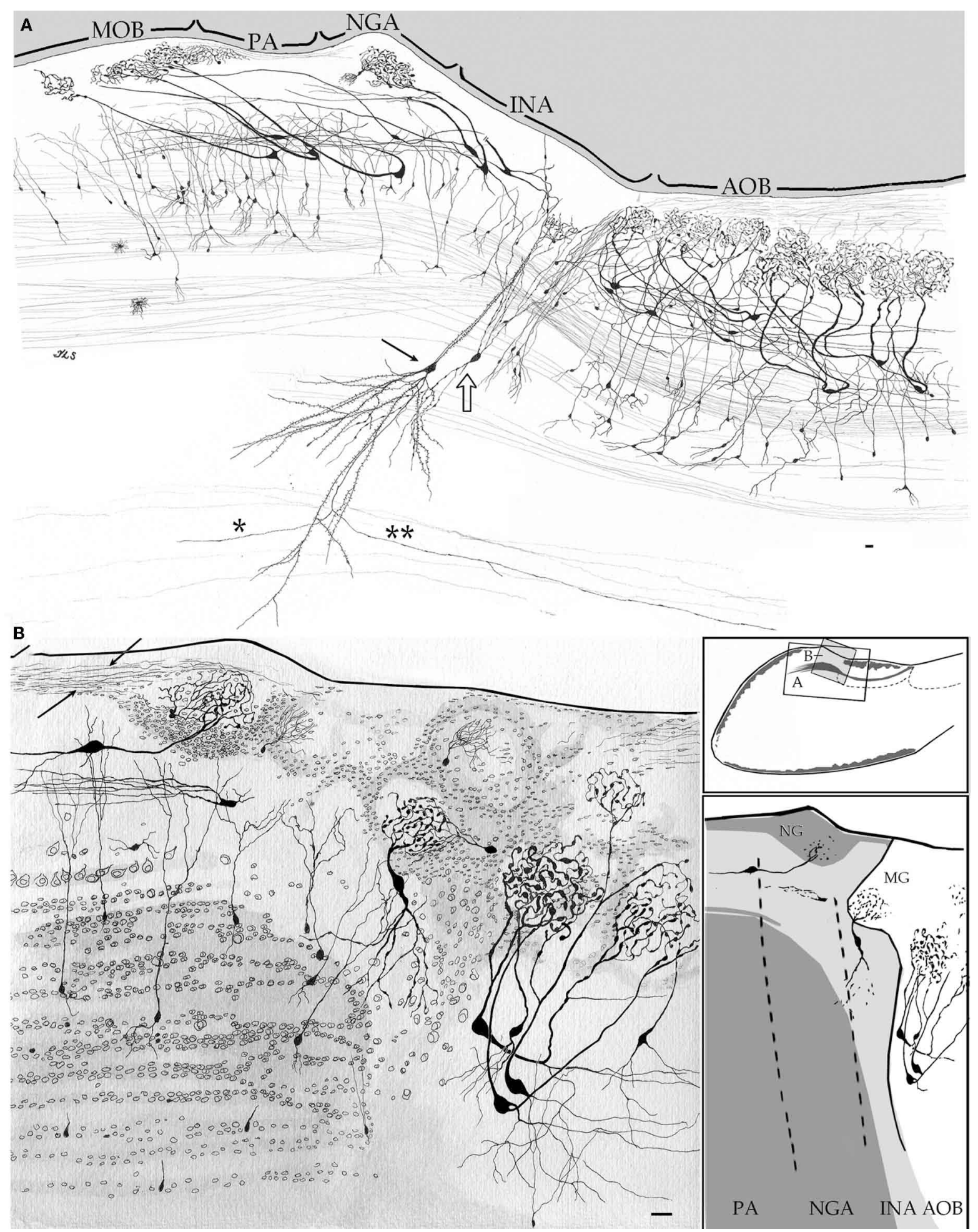

FIGURE 5 | Camera lucida drawings from sagittal sections through the olfactory limbus and adjacent structures. (A) The drawing accounts for the cellular contents and parceling in the olfactory limbus. Note that glomeruli in the main olfactory bulb (MOB) receive dendrites from mitral cells whose somata lie in the preofactory (PA) and necklace (NGA) areas of the olfactory limbus. A projecting interstitial neuron of the bulbi (arrow) lying deep in the homonymous area (INA) sends a descending axon that forks into rostrally (asterisk) and a caudally (double asterisk) directed branches. Interstitial neuron of the bulbi, interneuron (hollow arrow). (B) Drawing showing the neuronal distribution as seen in a specimen after a two-step strain, Golgi-Cox-Nissl. Arrows, fibrils arising from a necklace glomerulus; PA, NGA, INA, preolfactory, necklace glomeruli, and interstitial areas. Scale bars $=30 \mu \mathrm{m}$. Adult rat brain, rapid-Golgi (A), and Golgi-Cox-Nissl (B) techniques. 
MOB and AOB forms a well-defined layer, in the deep INA acquires a reticular appearance due to scattered myelinated fibers and small bundles that, as a rule, diverge in various directions (Figures 3E,5A).

\section{CYTOLOGY OF THE OLFACTORY LIMBUS}

Although the neuron phenotypes identified thus far in the OL are, in most respects, comparable to those observed in the MOB, they exhibit a different organizational strategy. In fact, the laminated appearance of the $\mathrm{MOB}$ and $\mathrm{AOB}$ observed in anilinestained specimens (Figures 2,3,4), that results from the layered coalescence of somata, is modified in the PA and NGA areas, and lost in the INA. This laminar disruption and the ensuing assorted distribution of neurons have little repercussion in the basic somato-dendritic features of the neurons. In fact, virtually all neuron-types observed throughout the olfactory cortex correspond to those seen in the OL although it must be stressed that here they exhibit curved, bent, or even twisted processes. This regional cellular pleiomorphism is better evidenced in specimens processed with a combination of silver and aniline techniques (Figures 5B,6).

The first and perhaps most obvious, OL specialization is that a set of mitral cell somata lie posteriorly with respect to their tributary glomeruli (Figure 5A). Consequently, apical dendrites arising from mitral cells in the OL run diagonal, nearly horizontally, to reach glomeruli that are located more rostrally. Clearly, the caudal displacement of the mitral cell somata with respect to their tributary glomeruli lying rostrally, differs from the vertical ascent normally observed for glomerular dendrites of mitral cells in the MOB (Figures 4A,B in Larriva-Sahd, 2008). That conclusion that tilted apical dendrites are a distinctive feature of mitral cells in the OL is afforded by the absence of them in the caudal aspect of the MOB, beyond the OL domain (Figure 7). In short, the "glomerular shift" observed in the OL yields to mital cell somata and their associated interneurons and granule cells are located caudally with respect to their tributary glomeruli (Figure 5A). Although dendritic polarization displayed by some mitral cells does not seem to apply to the tufted (Figure 6), shortaxon (Figure 8) or granule cells, more subtle variations in dendritic bending or even twisting can also be observed throughout the OL (Figures 5A,B,6).

In the deep area of the INA, just anterior to the internal cellular and LOT layers of the AOB, there is a streak of medium to large-sized neurons. These neurons whose somata were described in Nissl-stained specimens from hamster (Lohman, 1963; Lohman and Mentink, 1969), correspond to those collectively termed interstitial neurons of the bulbi (INBs) (LarrivaSahd, 2008) (Figures 3E,5A,8C). On cytological grounds INBs actually include two cell types, namely, pyramidal-like or projecting (INBp) and interneurons or intrinsic neurons (INBi). Like elsewhere in the neo-and olfactory cortices, pyramidal-like INB's represent the out-put cell. Most INBp dendrites exhibit a moderate to high number of spines and, as implicit, mimic the structure of their neo-cortical homologs. A striking feature of the INBp axon is that, having descended to the deep bulbar white matter, it divides into an anterior and a posterior (i.e., descending) fibril (Figures 5A,6C), in the same fashion as that described by Valverde (1965) in the new-born rodent anterior olfactory nucleus. A typical INBi has a bottle-shaped soma with varicose, bold dendrites. The axon of an INBi arises from a proximal dendrite (Figures 8E,F) or, less frequently, from the soma itself (Figure 8C) (see Larriva-Sahd, 2008). Soon afterwards, the INBi parent axon divides dichotomously at relatively short intervals (i.e., $<30 \mu \mathrm{m}$ ) thereby originating a dense axonal framework that distributes in the neuropil of the INA and in the adjacent granule and internal cellular layers. Although an INBi shares striking
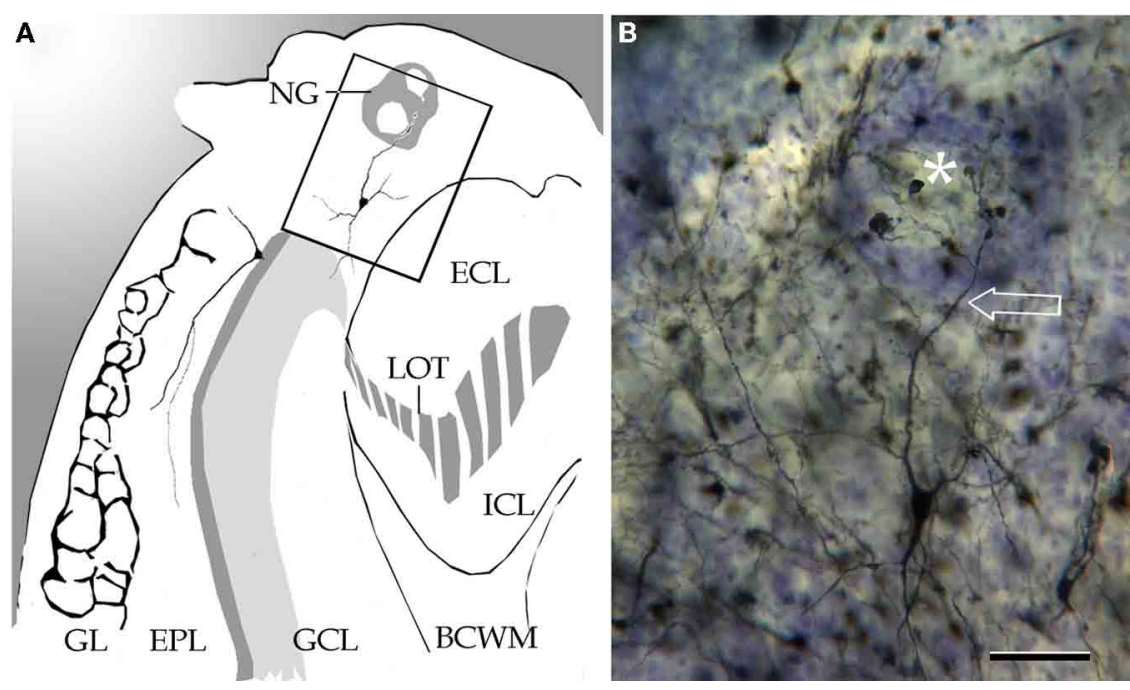

FIGURE 6 | Coronal section through the left olfactory bulb. (A) Diagramatic drawing showing a necklace glomerulus (NG). BCWM, bulbar core white matter; ECL, external cellular layer; $\mathrm{EPL}$, external plexiform layer; $\mathrm{GCL}$, granule cell layer; $\mathrm{Gl}$, glomerular layer; ICL, internal cellular layer; LOT, lateral olfactory tract. (B) A tufted cell sending a glomerular dendrite (arrow) to a necklace glomerulus (asterisk). Adult rat brain, Cox-Nissl technique. Scale bar $=50 \mu \mathrm{m}$. 


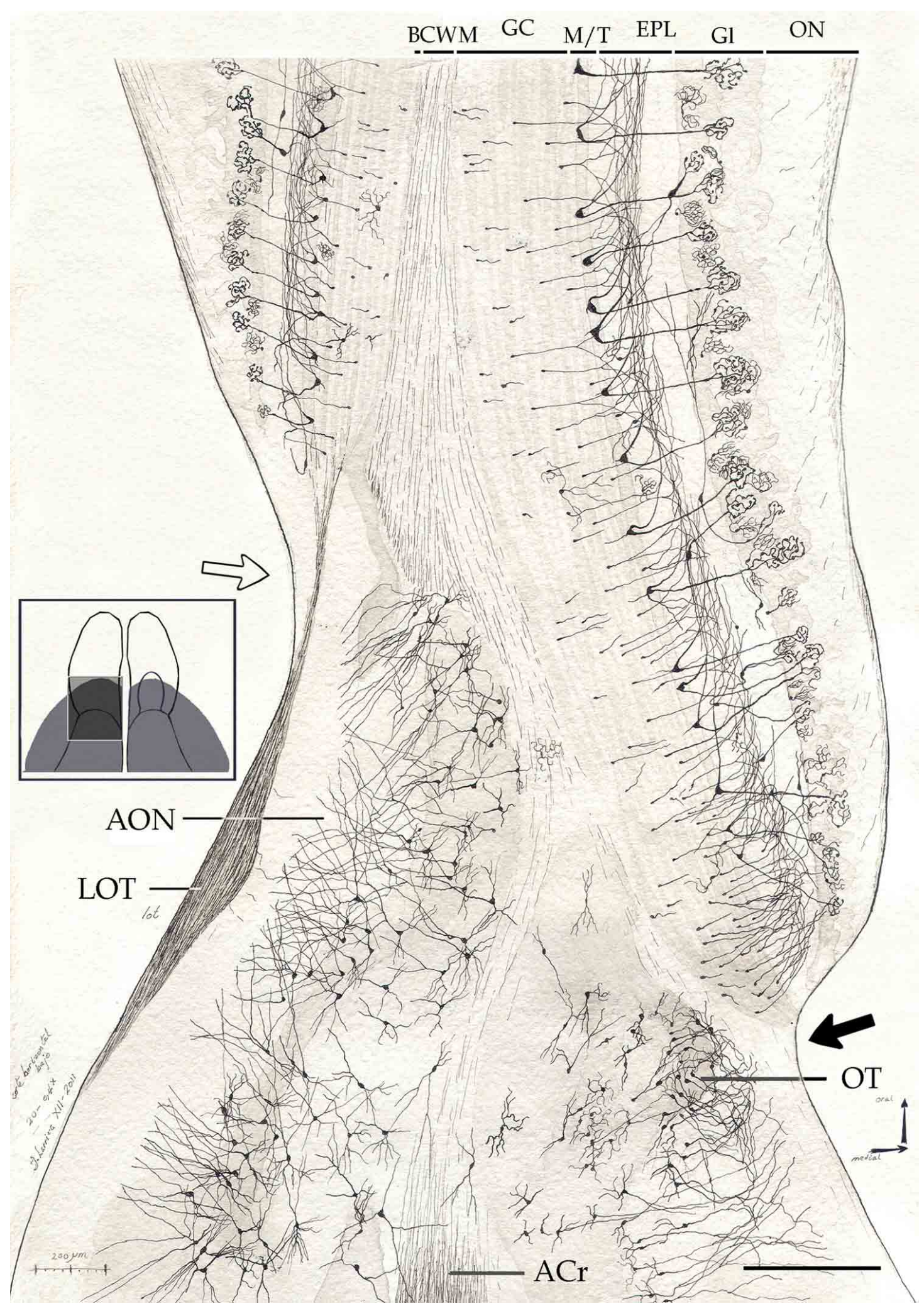

FIGURE 7 | Survey camera lucida drawing from the olfactory peduncle in a horizontal section. Note the mode of resolution of the main olfactory cortex at the medial (black arrow) and lateral (hollow arrow) aspects of the fissura circularis. $\mathrm{ACr}$, anterior commissure, pars rostralis; $\mathrm{BCWM}$, bulbar core white matter; EPL, external plexiform layer; GC, granule cell layer; Gl, glomerular layer; LOT, lateral olfactory tract; M/T, mitral-tufted cell layer; ON, olfactory nerve layer; OT, olfactory tubercle. Cox-Nissl technique, adult rat brain. Scale bar $=200 \mu \mathrm{m}$. 
A

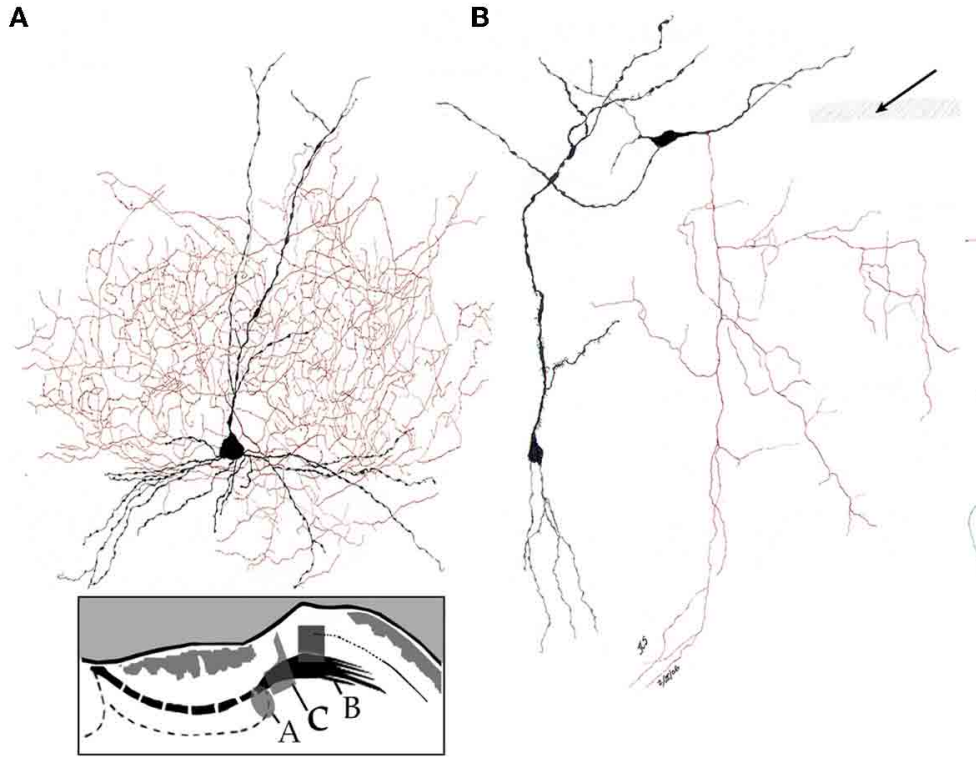

C

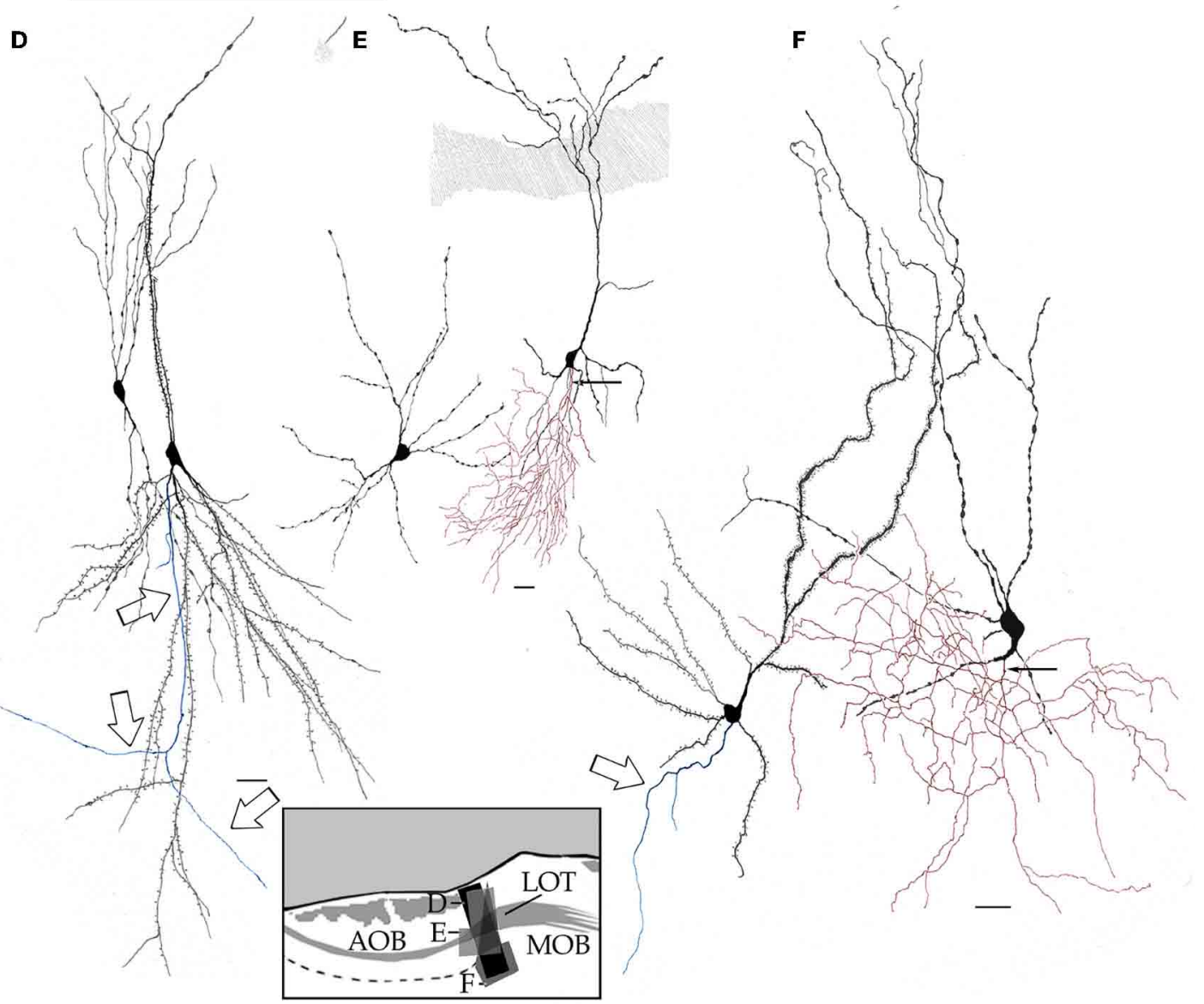

FIGURE 8 | High magnification drawings from bulbar neurons with projecting (blue) and local (red) axons. Somata and dendrites from the latter are nearly identical in shape, thickness, and varicosities. (A) Main accessory cell of the accessory olfactory bulb with a profuse axonal (red) field. (B) Deep short axon cell whose descending axon (red) distributes in the granule cell layer of the main olfactory bulb.

(C) Two interstitial bulbar interneurons with ascending axon and a projecting cell whose axon (green) divides into two descending collaterals. (D) Examples of interstitial neurons. The projecting cell (right) emits a descending axon (arrows). (E) A projecting cell whose parent axon provides a huge number of collaterals to the adjacent neuropil. (F) Pyramidal-like and a short-axon neurons in the alpha component of the anterior olfactory nucleus. Adult rat brain rapid-Golgi method. Scale bar $=15 \mu \mathrm{m}$. 
somato-dendritic similarities with certain MOB (Macrides and Davis, 1983; Kosaka and Kosaka, 2011) AOB (Larriva-Sahd, 2008) and medullary bulbar area (Paredes and Larriva-Sahd, 2010) interneurons, its axon is primarily distributed in the adjacent INA neuropil.

\section{Regional differences of the olfactory limbus}

The lack of a lattice-like, linear array displayed by most biological objects applies to the structure of the OL in that it varies from one histological section to the next. Although the tripartite division of the OL recommended here persists throughout the medial-lateral extent of the main-AOB interface, subtle differences are evidenced in successive sections through the OL (Figure 4). First is the presence of one or two small glomeruli that lie anterior aspect of the AOB. These glomeruli that ride on INA, appear to be part of the "modified glomerular complex" observed by Greer et al. (1982) in the newborn rat, and are most evident in sections through the medial half of the AOB. Serial sections depict that these are, in fact, smaller and inconstant throughout the rostral AOB. The same applies to the large NG found in the homonymous area, that is frequently seen in sections through the medial AOB half (Figures 4B-D), and is less evident or even absent in more lateral sections (Figures $\mathbf{4 F}-\mathbf{I}$ ). The medial and lateral aspects of the $\mathrm{AOB}$ are bounded by the $\mathrm{MOB}$ anteriorly and by the dorsal $\mathrm{AON}$, caudally. Hence, the confluence of the three distinct cortices at either side of the $\mathrm{AOB}$ gives rise to a medial and a lateral olfactory "triad." Due to the caudal expansion of the MOB, the medial triad is located caudally with respect to the lateral one. Further, the lateral olfactory triad is asymmetrical in that it accepts the distal processes of pyramidal-like cells (P-L), whose somata lie at the base of the AOB (see below) (Figure 9). Lastly, one can appreciate in successive longitudinal sections through the olfactory bulb that two elements of the OL, the PO and NGA, persist throughout the entire caudal ribbon of the MOB cortex with a progressive decrease in thickness along the fissura circularis (Figure 7) that defines the caudal end of the MOB.

Summarizing, the OL, a broad area of interaction between the MOB and AOB is characterized by a partial or complete modification of the laminar plan of organization observed throughout the bulbar cortex. Despite the disruption of the strata the OL is composed of three distinct components having, in turn, predictable histological and cytological organization.

\section{ALPHA GROUP OF THE ANTERIOR OLFACTORY NUCLEUS General organization}

Unstained (Figure 1) or aniline-stained (Figures 2,3A,B,C,4F) sections through the olfactory bulb show a distinct, fusiform collection of neurons that parallels the middle third of the AOB. The nucleus consists of a compact neuronal cluster measuring $100 \times$ $150 \times 650$ microns in the horizontal, vertical, and anteroposterior
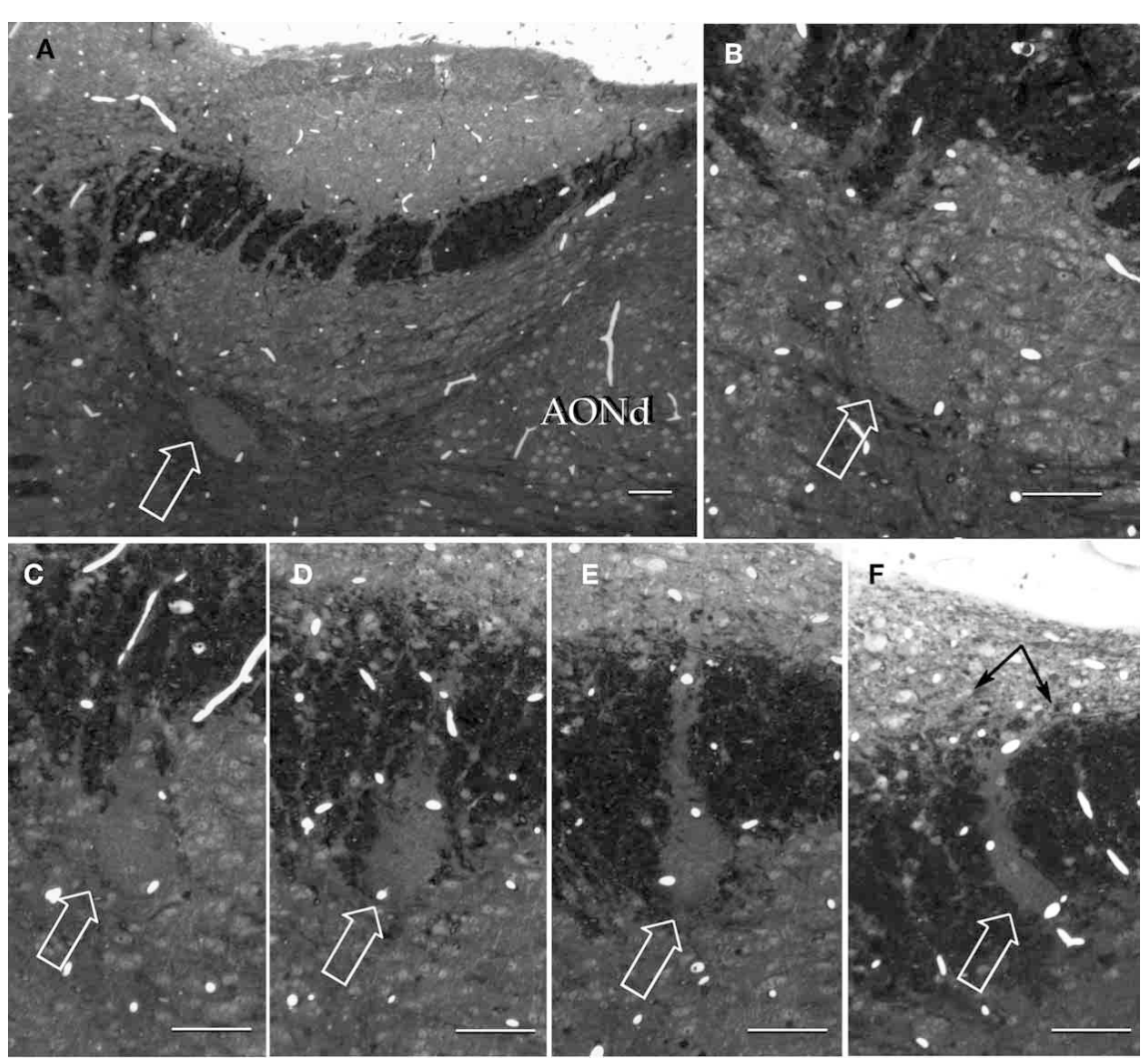

FIGURE 9 | Semi-serial, sagittal sections through the accessory olfactory bulb Note the progressive ascent of the dendritic bundle (hollow arrows) from medial $(A)$ to lateral $(F)$, to resolve under (black arrows) the pial covering in F. Adult rat brain, epon embedding, one-micron thin section, toluidine-blue staining. Scale bars $=50 \mu \mathrm{m}$. 


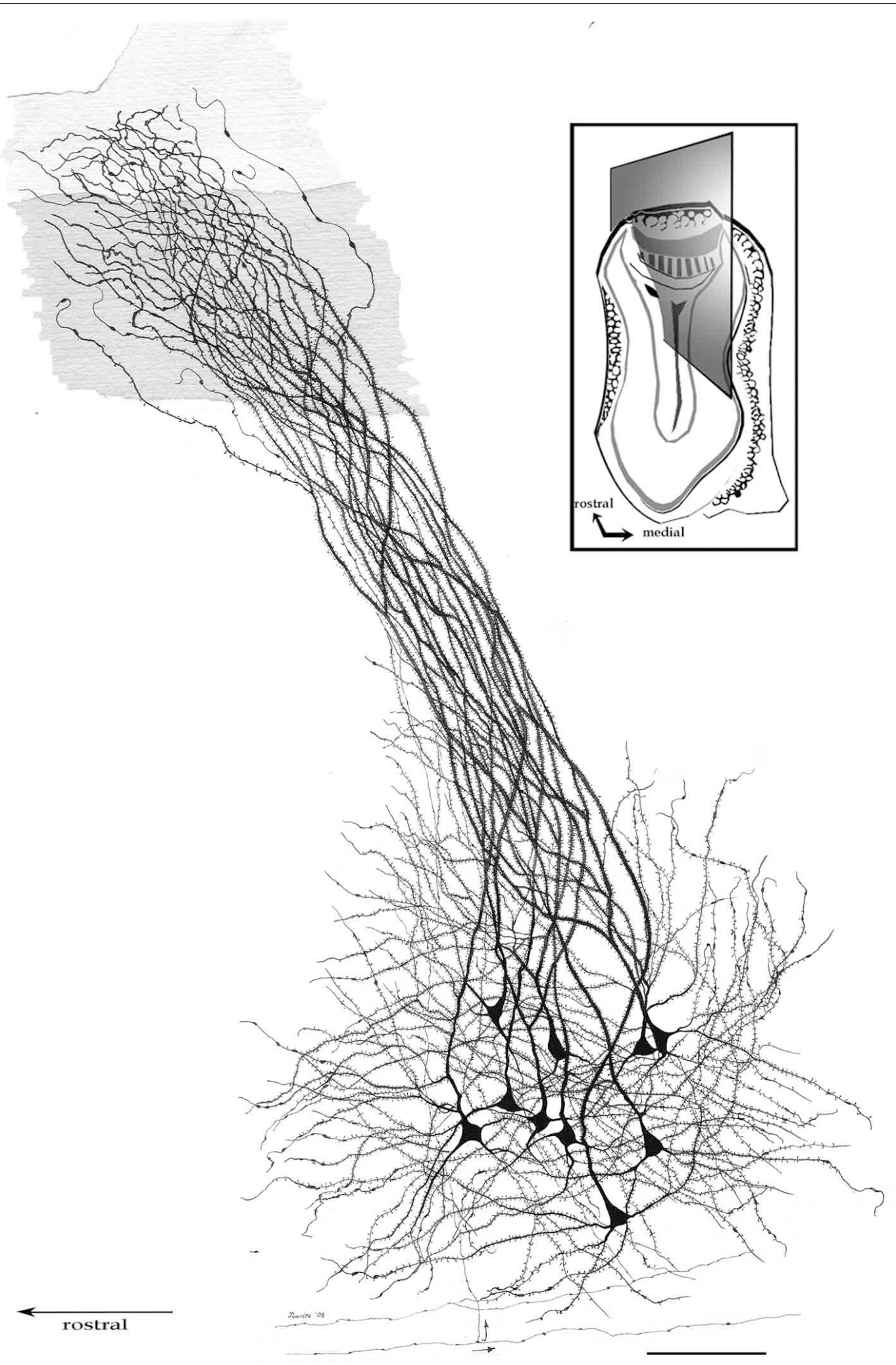

FIGURE 10 | Pyramidal-like cells in the alpha component of the anterior olfactory nucleus. The spiral path followed by apical, spiny, dendrites in their ascent can be seen. Note that distal, aspiny, dendrites impinge on the lateral olfactory tract (shaded). Fibers at the bottom belong to the deep bulbar white matter; one of them sends along collateral (arrow) that penetrates the nuclear neuropil. Adult rat brain, sagittal section, rapid-Golgi technique. Scale bar $=100 \mu \mathrm{m}$. 


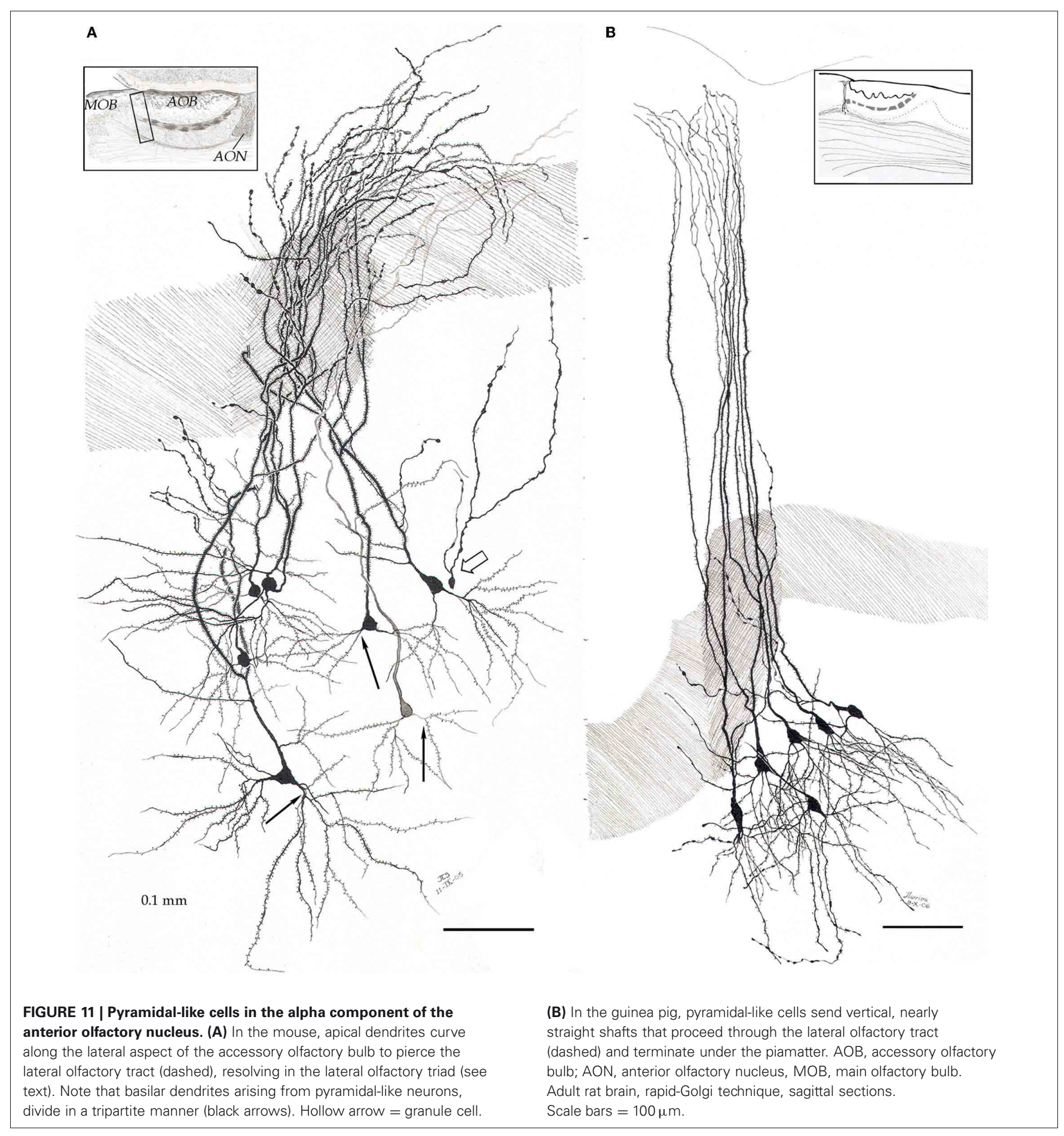

axes, respectively. In about two out of 10 specimens, the aAON shifts its position underscoring the rostral third of the $\mathrm{AOB}$ (Figures 3A,B,C). Regardless of its location the bulbar core white matter encases the nucleus. High magnification inspection of the aAON reveals that it is composed of a double population of neurons (2C and 3C). A first or pyramidal-like neuron (P$\mathrm{L})$, whose soma is triangular, measures $20-27 \mu \mathrm{m}$ in its longest axis. The nucleus of a P-L is rounded and contains a distinct nucleolus surrounded by a basophilic cytoplasm due to patches of Nissl substance. A small satellite cell is commonly associated with P-Ls. A second, smaller neuron consists of a round to pearshap cell measuring $13-16 \mu \mathrm{m}$ in its widest axis. The nucleus is also rounded or oval containing coarse granular chromatin and two or three small indistinct nucleololi. Cytoplasmic basophilia is concentrated at the two cellular poles. Mophometry discloses that the aAON somata bear significantly different, albeit larger 
(i.e., $156 \mu \mathrm{m}^{2}$ ), somatic areas than those from the dAON (i.e., $124 \mu \mathrm{m}^{2}$ ) (see Brunjes et al., 2011).

\section{Principal cell}

By-and-large, pyramidal-like neurons (P-L) are the most common neuron-type in the aAON. Although P-Ls lie in the nuclear domain, their ascending dendrites that proceed dorsally, buildup a well-defined bundle. These ascending dendrites that follow an helicoidal path, pierce the lateral part of the INA to terminate underneath the pial covering (Figures 9,10). The overall direction of the resulting bundle is not straight, especially in the adult rat (Figure 10) and mouse (Figure 11A). In these species, as soon as the apical dendrite leaves the nuclear domain, it arches antero-laterally, avoiding the $\mathrm{MOB}$ and $\mathrm{AOB}$ to resolve in the lateral olfactory triad. Because of this heterodox trajectory, diagonal (Figure 10) or serial (Figure 9) sections are required to visualize the full dendritic arbor of a pyramidal cell. Alternatively, pyramidal cells from guinea-pig specimens, whose principal cell exhibits straight apical dendrites, may suit that purpose (Figure 11B). The tridimensional distribution of P-L processes with respect to the adjacent structures is diagrammatically depicted in Figure 12. Occasional (i.e., about 2 from 10) pyramidal cells possess one or two supernumerary, thick dendrites that arise from the base of the main apical branch, running diagonally. As soon as ascending dendrites pierce the LOT they divide once or twice to form distal terminal tributaries. A distinctive feature of these distal branches is the presence of bold, rounded, varicosities united by thin cytoplasmic shafts. Like typical isocortical pyramids (Feldman, 1984), most P-L's dendrites are densely covered by numerous spines (Figures 13,14D), although terminal branches are virtually devoid of them (Figures 10,11). A peculiar feature of basilar dendrites of a P-L is that they divide originating three daughter dendrites (Figure 11A). This tripartite branching assumed by basilar dendrites distinguishes a P-L from other neo-cortical pyramids (Lorente de Nó, 1949). The axon of a P-L behaves in the same manner as most pyramidal cells observed in the INBp (Figure 11A) and olfactory peduncle (i.e.,

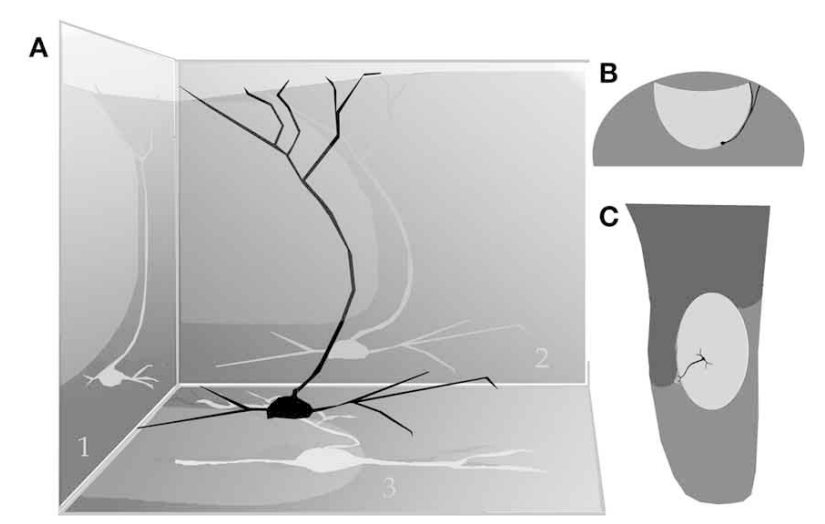

FIGURE 12 | (A) Diagram showing the path of the pyramidal cell (black) apical dendrite with respect to the anterior (1), lateral (2), and basal (3) aspect of the accessory olfactory bulb (shaded, egg-shaped). (B) Dendritic trajectory of a pyramidal-like cell with respect to the accessory olfactory bulb (lighter) in a coronal view (lateral, right side). (C) Dorsal view. anterior olfactory nucleus) (see Valverde, 1965), since it descends to the bulbar core white matter leaving 2-8 recurrent collaterals that distribute in the overlying internal cellular layer of the AOB (Figure 13). Distally, the stem axon divides, originating two fibrils that proceed further caudally and rostrally, respectively (14B).

\section{Interneurons}

One out of 10 neurons observed in the aAON consists in an interneuron (INBi) (Larriva-Sahd, 2008). INBis appear to correspond to the pear-shaped somata observed in aniline-stained specimens (Figure 2C). The smato-dendritic features of INBi (Figure 13) mimic, in several respects, those observed in other aspiny short-axon neurons in the bulbar cortex (Figures 8A,B) (see Figure 10, Larriva-Sahd, 2008), and medulla (Paredes and Larriva-Sahd, 2010) in that the soma is smooth, originating two or three primary dendrites that soon afterwards (i.e., $<30 \mu \mathrm{m}$ ) give rise to secondary and tertiary dendrites, usually the most distal branches. Dendrites are, as a rule, varicose and virtually devoid of spines (Figures 13,14C,D). What seems to be unique of aAOB intrinsic neurons from other bulbar interneurons is that their axon distributes primarily in the aAON neuropil, creating a dense axonal framework in the nucleus proper. As a matter of fact, the interneuron axon is an important source of intrinsic fibrils that structure the aAON neuropil (Figures 13A,14C), although is not uncommon for axon fibrils to invade the adjacent external cellular layer of the AOB (Figure 13A). At high magnification one can observe that the axon displays numerous en passage and terminal boutons (Figure 14C) unlike terminal fibrils from other sources (Figures 13B,14A,B,E). Additional fibrils in the aAON neuropil include collaterals from the P-L axon (Figures 13,14B) and from the deep bulbar white matter (Figure 14E). In precis, the aAON neuropil is composed of terminal axonal fields arising from the P-L, interneurons and from the surrounding white matter.

\section{Immunocytochemistry}

Light microscopic observation of specimens incubated with antibodies to GAD67, reveals that the aAON is composed of immunoreactive (GAD67-I) cells (Figure 14F), and numerous GAD67-I punctae (14G). GAD67-I neurons display diffuse, brownish reaction products throughout the cytoplasm acquiring a ring-shape due to a pale nuclear area.

\section{ELECTRON MICROSCOPY AND IMMUNOCYTOCHEMISTRY Neurons}

Survey electron micrographs of the aAON (Figure 15) reveal that it is composed of cellular clusters of two or three neurons surrounded by a relatively homogeneous neuropil with a paucity of thin myelinated fibers. Neurons are rounded or spindle-shaped with a central nucleus of smooth profile. A signal feature of aAON neurons is that their somata appose each other directly, without an intervening neuropil or glia. Occasional satellite cells (Figures 2C,16B) or astrocytes (Figure 16C) lie adjacent to the neuronal clusters. The neuronal nucleus is generally smooth and it contains abundant euchromatin with small, scattered chromatin aggregates that are embedded in a lowdensity karyoplasm. A distinct solitary nucleolus may be seen 


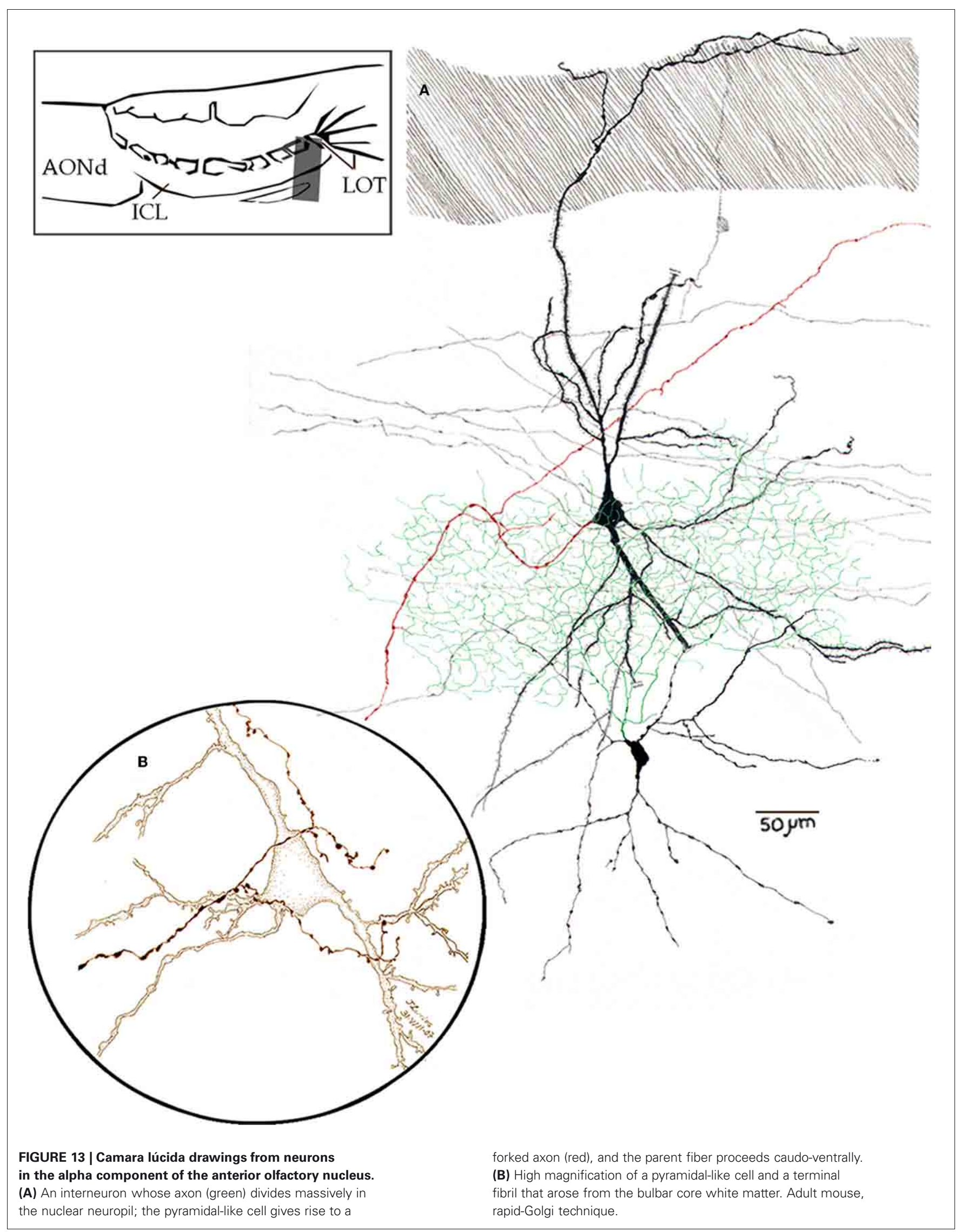



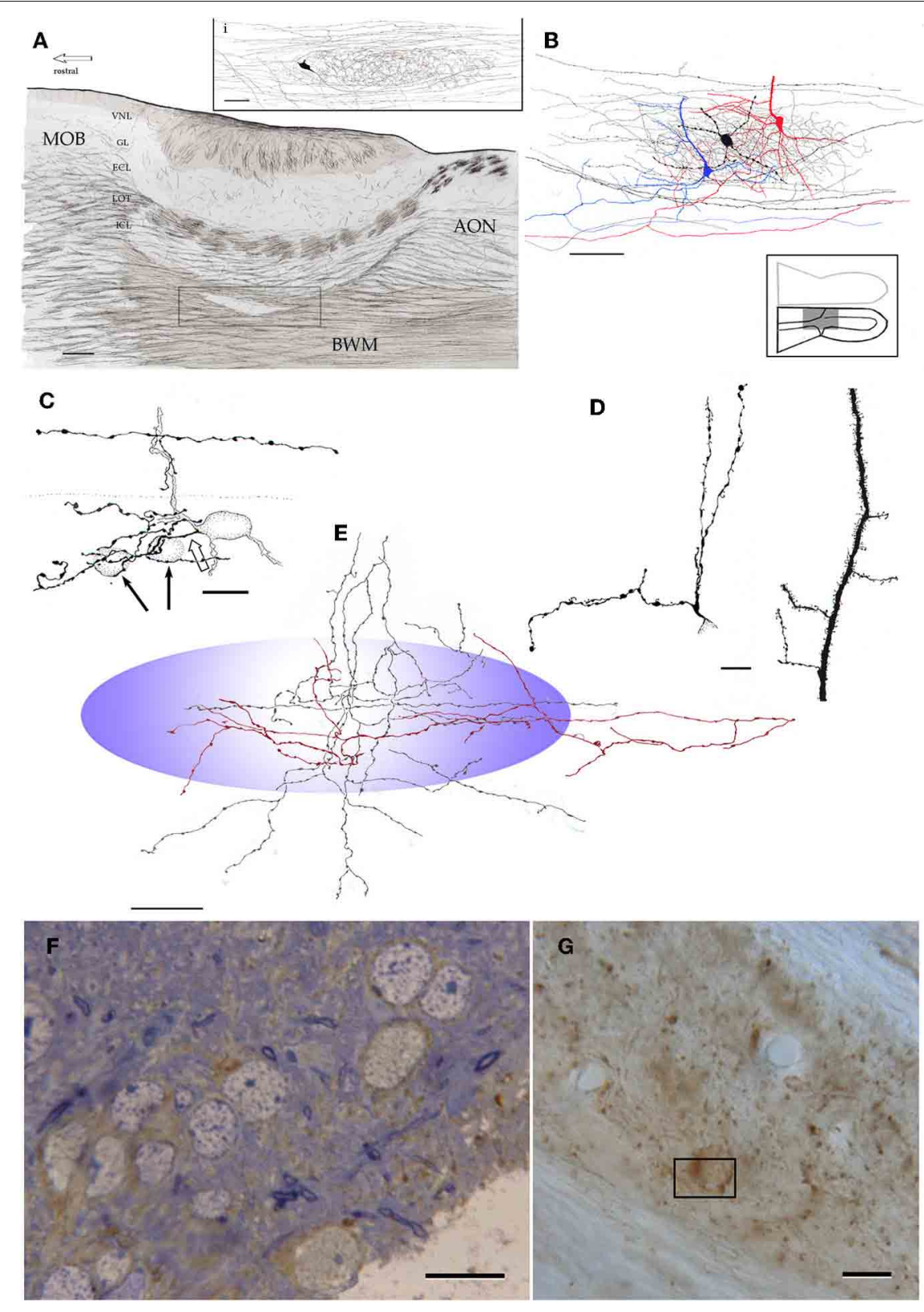

\section{FIGURE 14 | Microscopic organization of the alpha component of the} anterior olfactory nucleus. (A) Fiber systems associated with the olfactory bulbar cortex and alpha component of the anterior olfactory nucleus (framed). The inset shows the distribution of a single axon and its terminal field in the nuclear neuropil. (B) Contribution of the pyramidal-like cell (blue and red) and interneuron (black) axons to the nuclear neuropil. (C) High magnification view of the soma and proximal dendrites of an interneuron in the alpha component; an axon collateral arising from a fiber in the deep bulbar white matter at the top. (D) Proximal dendrites of a short-axon (left) and pyramidal-like neurons.
(E) Contribution of axons and their collaterals to the neuropil of the alpha component (blue). Proximal dendrites from an interneuron (left) and a pyramidal-like cell. Note that the latter is covered by numerous dendritic spines. (F) Immunohistochemistry for glutamic acid decarboxylase, isoform 67 (GAD67) in the alpha component in a one-micron thin section counterstained with toluidine-blue. (G) Unstained, plastic-embedded section showing the pattern of GAD67 immunoreactivity in the alpha component. Note the lack of labeling in the white matter (upper right and lower left). Scale bars $=100 \mu \mathrm{m}$ in $\mathbf{A}, 20$ in inset and $\mathbf{E}, 40 \mathrm{in} \mathbf{B}, 15 \mathrm{in} \mathbf{C}, \mathbf{D}, \mathbf{F}$ and $\mathbf{G}$. occurring centrally or adjacent to the nuclear envelope. The cytoplasm exhibits focal areas of rough endoplasmic reticulum (RER) adopting the form of isolated, scattered cisternae. Adjacent to the RER there are two or three Golgi areas associated with membrane-bounded structures with high electron-dense matrices (Figure 16A) and multivesicular bodies. The cell profile is smooth although occasional indentations due to synaptic terminals can be seen. In appropriate sectioning planes one or two proximal dendrites from the somatic cytoplasm can be seen. 


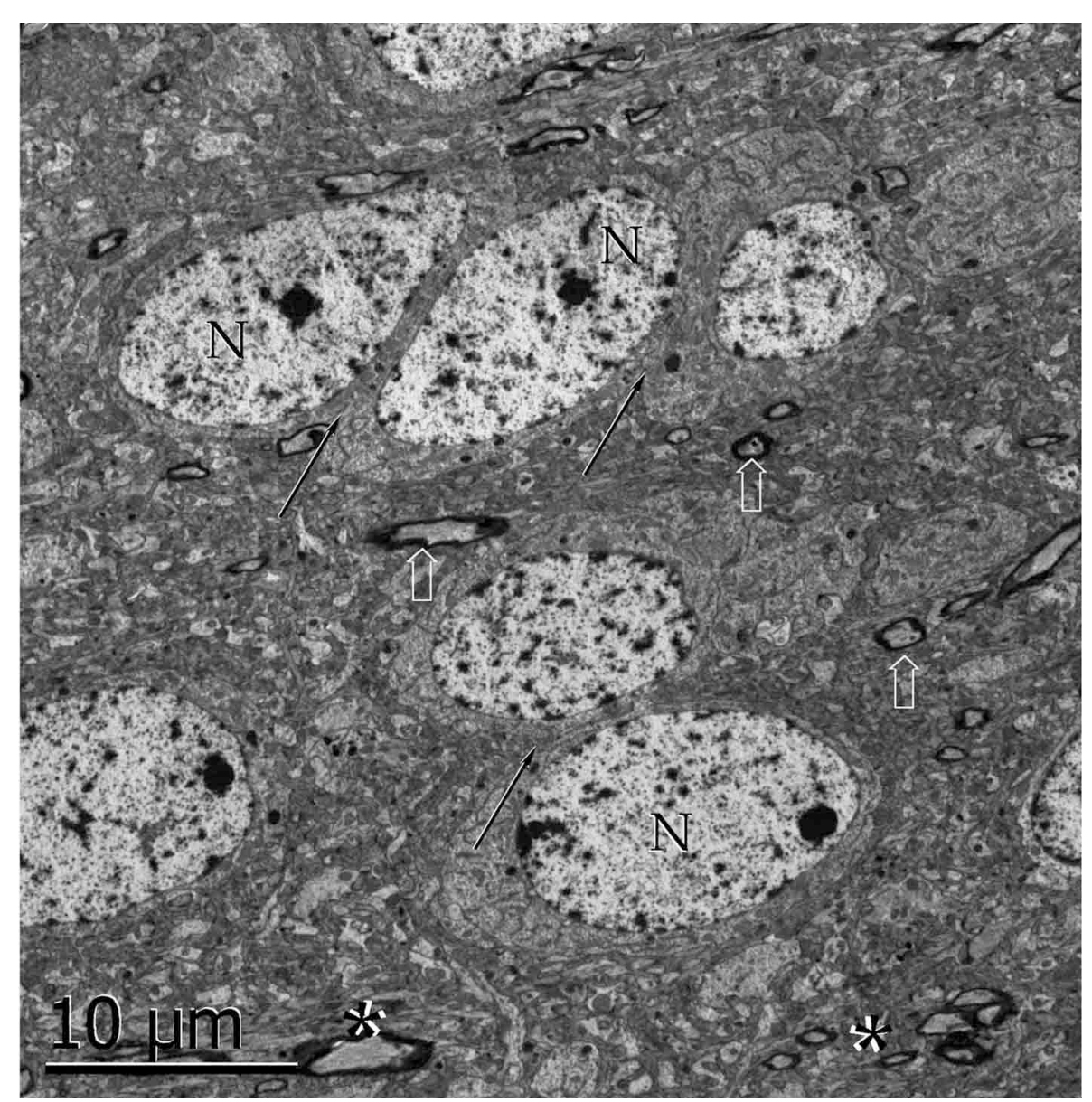

FIGURE 15 | Survey electron micrograph of neurons in the alpha component of the anterior olfactory nucleus. Note the apposition of somata (arrows). $\mathrm{N}$, cell nucleus; arrows, myelinated axons. Uranium-lead contrast, adult rat brain.

\section{Neuropil}

The aAON neuropil proper is relatively homogeneous throughout the nucleus. In addition to isolated myelinated fibers (Figure 15), the neuropil exhibits the following specializations. Asymetrical axo-spinous contacts account for most (i.e., 92\%) of the contacts of the aAON neuropil, followed by axo-shaft (5\%) and occasional axo-somatic $(<3 \%)$ contacts (17A and B). Somatic terminals include asymmetrical and reciprocal (Figure 17C) synapses, in order of frequency. The latter are indistinguishable from those in the rodent MOB, described earlier between mitral cells somata or their dendrites (Hirata, 1964, see Toida et al., 1996).

\section{Immunocytochemistry}

Scattered somata and synapses exhibit immunoreactivity to the glutamic acid decarboxylase 67 isoform (GAD-I) (Figure 18A). A set of neurons contain a coarse electron-dense material free in the cytoplasm or associated to the Golgi apparatus; this material is similar in appearance to that corresponding to immunoreactive sites (Figure 18B) (Toida et al., 1996; Barbaresi, 2005). GAD-I was also found in synaptic boutons, most commonly in axo-shaft and axo-somatic terminals (Figure 18D); in either case the postsynaptic element was devoid of GAD-I material. Furthermore, no GAD-I was found in axo-spinous terminals (Figure 18C). The frequent association of the GAD-I material precluded identification of the active zones associated with the synaptic apparatus and, therefore, their distribution at either side of the synaptic cleft.

\section{DISCUSSION}

Correlates for the functional involvement of the OL, should be based on the various earlier observations in this poorly understood area. Perhaps the first observation suggesting glomerular differentiation throughout the bulbar cortex was made in the new born rat and showed that glomerular glucose uptake at the MOB-AOB junction was enhanced following exposure to a nipple-derived pheromone. The term "modified glomerular complex" (MG) was coined to refer to these specialized glomeruli (Teicher et al., 1980; Greer et al., 1982). Further support for a bulbar parceling was supplied by the identification of a group of glomeruli that crown the caudal end of the MOB. Because these 8-9 glomeruli are mutually linked among them by fibrillar bridges, the term "necklace glomeruli" (NG) was introduced by Shinoda et al. (1989). On the basis of their connectional and immunohistochemical characteristics, the same authors regarded 


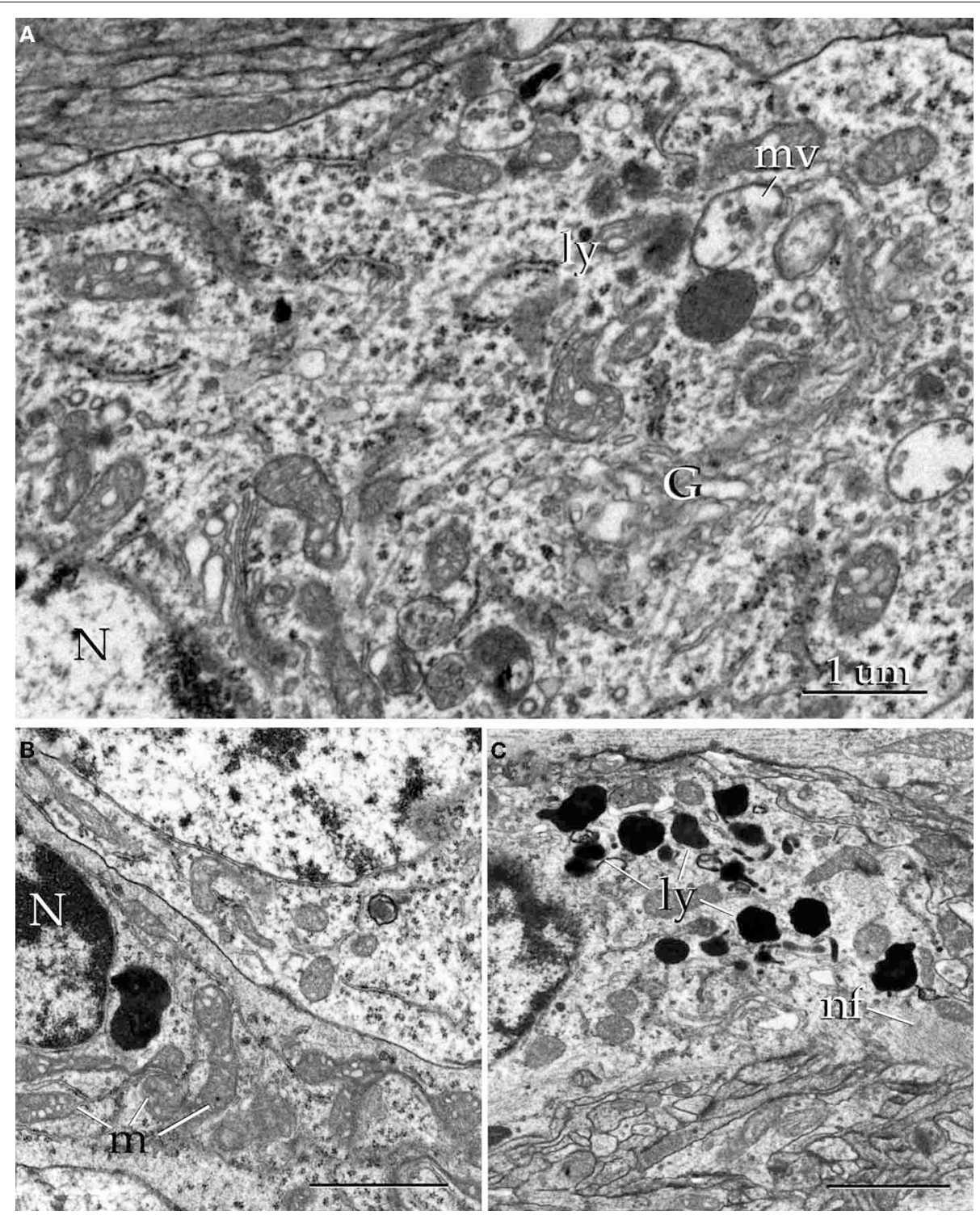

FIGURE 16 | Electron micrographs of the alpha component of the anterior olfactory nucleus. (A) Juxtanuclear cytoplasm of a neuron containing Golgi apparatus (G), electron-dense bodies (ly), and multivesicular bodies (mv). N, cell nucleus. (B) Nucleus (N) and cytoplasmic contents from a satellite cell. m, mitochondria. (C) Cytoplasm from an astrocyte containing numerous electron-dense structures (ly) and filament bundles (nf). Uranium-lead contrast, adult rat brain. Scale bars $=0.5 \mu \mathrm{m}$ in $\mathbf{B}$ and $\mathbf{C}$ one of the MG as an integral part of the NG system. Present observations support the idea that one or two glomeruli from the former $\mathrm{MG}$ belong to the oral part of the AOB. In fact, inspection of the foremost part of the AOB show that glomerular dendrites of overlaying glomeruli arise primarily from large principal cells therein (Figures 3A,5B). This observation provides structural evidence for the AOB involvement in the pheromonal activation observed in the MG (Teicher et al., 1980; Greer et al., 1982). Actually exposition to the male rat to female urine (Pereno et al., 2011) increases Fos expression in the rostral half of the $\mathrm{AOB}$ with respect to the caudal, reaching the peak in the foremost AOB (Honda et al., 2008). As a matter of fact, illustrations shown in the latter studies (Honda et al., 2008; Pereno et al., 2011) suggest that cells in the OL area described here are also activated by pheromone exposure of the male rat. Further, stimulation by odorants or pheromones brings about successive activation of the MOB and $\mathrm{AOB}$, reaching the peak in bold signal along the rosatral part of the AOB (Xu et al., 2005). Still another set of observations that distinguishes the OL from the rest of the bulbar cortex is its reception of axons arising in Grueneberg ganglion, a putative chemoreceptor located at the nasal vestibule (Grueneberg, 1973). In fact, Grueneberg ganglion projects to those glomeruli "in close apposition to the AOB" (Fuss et al., 2005), strengthen the notion that neurons there in are associated with chemosignal recognition and decoding (see Stowers and Logan, 2010). 


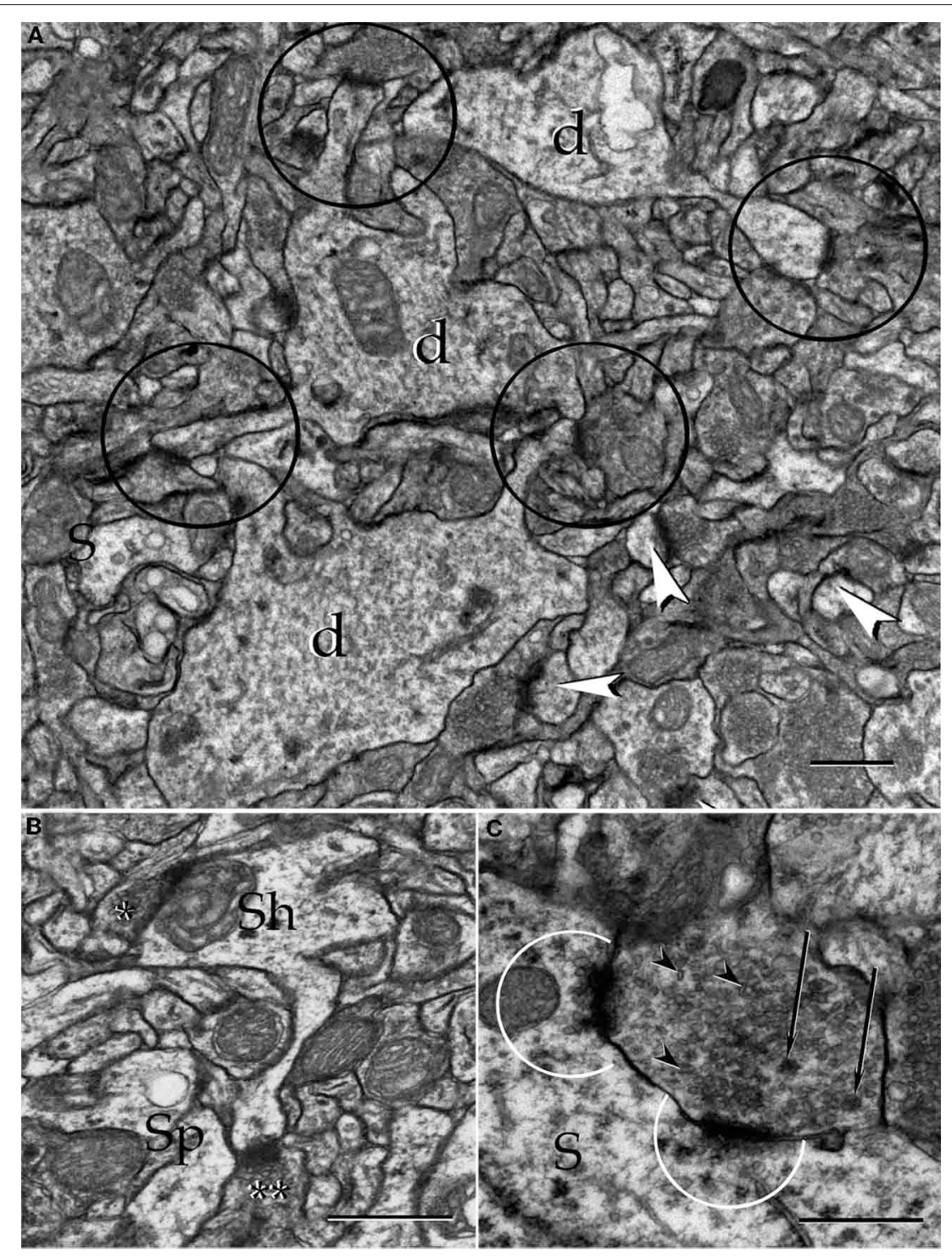

FIGURE 17 | Electron micrographs from the neuropil of the alpha component of the anterior olfactory nucleus. (A) Proximal dendrites (d) and axo-spinous, asymmetircal synapses, prevail in the neuropil. (B) An axo-shaft (Sh) and axo-spinous synapses. Asterisks, synaptic boutons. (C) A reciprocal synapse containing agranular (arrow-heads), and dense-core (arrows) vesicles establishes contact with the soma (S). Note the presence of numerous agranular vesicles in that part of the cytoplasm adjacent to the active zones (encircled). Uranium-lead contrast, adult rat brain. Scale bars $=1 \mu \mathrm{m}$ in $\mathbf{A}$, $0.5 \mu \mathrm{m}$ in $\mathbf{B}$ and $\mathbf{C}$.
An even more difficult task is to foresee the possible functional implication of our INBs described earlier (Larriva-Sahd, 2008) and ascribed here to the INA of the OL. To start with there is the association of the INB dendrites with fibers traveling in the LOT, a fiber system that conducts the efferent fibers arising from mitral/tufted and large principal cells, the only known output from the MOB and AOB, respectively. This association led me to speculate that the IFNs, which appear to be the foremost signature of cortical-like organization (i.e., afferent fibers, local circuit plus pyramidal cells), may represent a cellular substrate for relaying nerve impulses from both the $\mathrm{MOB}$ and $\mathrm{AOB}$. Although this hypothesis requires further physiological evidence our current work, indicating that neurons in the INA-OL respond to electrical stimuli applied separately to either the main or AOBs, enhances the validity of our recent proposal. Whichever functional involvement for the OL emerges from future research, our anatomical frame provides a structural base line to define the physiological role of the distinct areas and cell-types depicted here.

\section{THE ALPHA ANTERIOR OLFACTORY NUCLEUS: AN ORPHAN CELL GROUP?}

The aAON was first described by Ramón y Cajal who stated that, although neurons therein were resistant to silver impregnations, the cluster of neurons was composed of large, polygonal cells as revealed by aniline-stained specimens. Only a laconic statement about them was made: "neurons with large nuclei, surrounded 


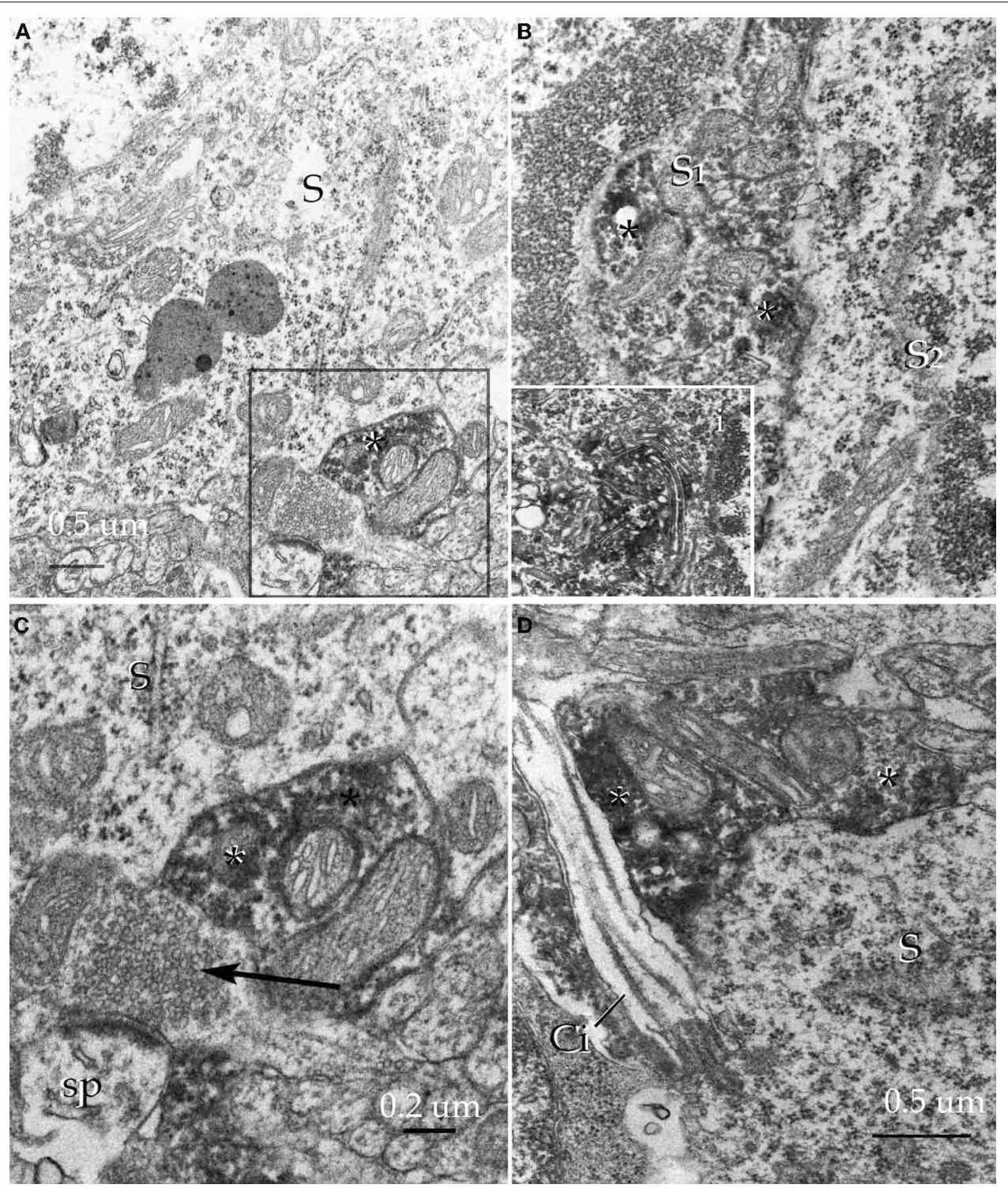

FIGURE 18 | Pre-embedding immunocytochemistry for glutamic acid decarboxylase, isoform 67 in the alpha component of the anterior

olfactory nucleus. (A) Adjacent to an unlabeled soma (S) an immunoreactive synaptic terminal (asterisk) can be seen. (B) Somata of an unlabeled (S2) and an immunoreactive (S1) neuron. Note the high electron density of the amorphous material (asterisks) corresponding to immunoreactivity. i. High magnification view of the immunoreactive material assoaciated with the cisternae of the Golgi apparatus. (C) A labeled juxta-somatic synapse (asterisk) adjacent to an axo-spinous terminal that is devoid of immunoreactivity. S, soma. (D) A putative axo-somatic bouton positive for GAD67 (asterisks); note the emergency of a cilium at the periphery of the soma (S). Uranium-lead contrast, adult rat brain. by a cytoplasm with fine granular chromatin resembling local association neurons, but having been unable to impregnate them with silver chromate, we ignore their structural characteristics and their connectivity as well" (Ramón y Cajal, 1904), closing by stating that this "foco de neuronas grandes" might correspond to short-axon neurons ("corpúsculos de Golgi") displaced from the granule cell layer of the AOB." In subsequent studies the same cell group was ascribed to an anterior component of the AON and, more recently, Valverde et al. (1989) termed it the alpha component of the AON. Actually the latter authors working in hedgehog specimens reported, for the first time, that the
aAON was composed of pyramidal cells wedged between the $\mathrm{M}$ and AOB; no short-axon neurons were noted. Our study confirms this observation and extends it to the adult rat, mouse and guinea pig, thereby adding further cytological characteristics about the pyramidal-like neurons in these species. Furthermore, a set of aAON neurons corresponds to typical short-axon cells (vide infra), suggesting that the internal circuitry may involve the same fundamental elements as the cortical units, described by Lorente de Nó (1949), namely, afferent fibers, short-axon, and projecting neurons. Our electron microscopic observations disclosed further information regarding the synaptic organization of the nuclear 
neuropil at the subcellular level as well as the mode of termination of putative inhibitory terminals showing GAD immunoreactivity (see Barbaresi, 2005). All together, these observations are relevant for the eventual understanding of both the internal nuclear circuitry and its physiological involvement. Lastly, the morphometric analysis of neuron-somata measurements indicates a difference between the dAON and aAON (see Brunjes et al., 2011) that, coupled with the difference of their overall appearance in both rapid-Golgi and aniline-stained specimens might underlie dissimilar physiological involvement.

\section{FUNCTIONAL CORRELATES FOR THE aAON}

In physiological terms, virtually nothing it is known about the aAON; however, some straightforward correlates, consisting with the structure and interactions of this nucleus can be made. In fact, afferent fiber systems that send terminal axonal fields or axon collaterals to aAON neurons derive from the deep bulbar white matter and from the LOT itself. Because the bulbar core white matter conducts fibers arising from the AON at either side of the brain (Valverde, 1965; DeCarlos et al., 1989; Yan et al., 2008), and because the LOT conducts fiber systems arising from the $\mathrm{MOB}$ and $\mathrm{AOB}$, a mandatory working hypothesis is that the aAOB decodes olfactory information, perhaps that related to both the main and accessory olfactory systems. The growing concept that olfactory glomeruli in the MOB project centrally, ipsi-, and contra-laterally in a highly ordered fashion (Yan et al., 2008; Stowers and Logan, 2010; see Baum, in this volume), opens the attractive possibility of defining the glomerular and central interactions of the aAOB (see DeCarlos et al., 1989), which would be a fundamental step towards defining the functional role of the aAON.

\section{NOVEL DOMAINS, NOVEL NEURONS?}

It has long been assumed that the heterogeneous class of interneurons lying in the deep olfactory bulb (i.e., granule cell and internal cellular layers of the $\mathrm{MOB}$ and $\mathrm{AOB}$, respectively) belongs to the "deep short-axon neurons" (López-Mascaraque et al., 1986, see Kosaka and Kosaka, 2011). Having added some candidates to this broad category it seems reasonable to outline our normative foundation to classify them into specific cell types (Larriva-Sahd, 2008, 2010; Paredes and Larriva-Sahd, 2010). Most neurons of the

\section{REFERENCES}

Barbaresi, P. (2005). GABAimmunoreactive neurons and terminals in the cat periaqueductal gray matter: a light and electron microscopic study. J. Neurocytol. 34, 371-487.

Brunjes, P. C., Kay, R. B., and Arrivillaga, J. P. (2011). The mouse olfactory peduncle. J. Comp. Neurol. 519, 2870-2886.

DeCarlos, J. A., López-Mascaraque, L., and Valverde, F. (1989). Connections of the olfactory bulb and nucleus olfactorius anterior in the hedgehog (Erinaceus europaeus). J. Comp. Neurol. 279, 601-618.
DeFelipe, J. (2002). Cortical interneurons: from Cajal to (2001). Prog. Brain Res. 136, 215-238.

Doetsch, F., García-Verdugo, J. M., and Álvarez-Buylla, A. (1997). Cellular composition and three-dimensional organization of the subventricular germinal zone in the adult mammal brain. J. Neurosci. 17, 5046-5061.

Eyre, M. D., Antal, M., and Nusser, Z. (2008). Distinct deep short-axon cell subtypes of the main olfactory bulb provide novel intrabulbar and extrabulbar GABAergic connections. J. Neurosci. 28, 8217-8229.

Feldman, M. (1984). "Morphology of the neocortical pyramidal neuron,"

central nervous system are profusely interconnected by numerous pathways. This richness of connections is due not only to the high number of neurons and pathways but also to the branching of the axons and their collaterals and to the overlap between the fields of distribution of the branches from different axons (Lorente de Nó, 1938). Unlike most mammalian non-neural epithelial cells that exhibit a relative simple cellular interaction with their homologs, neurons, although alike, may usually be surrounded by discreet yet remarkably different driving influence, the influence indulge by axonal inputs. Thus, defining the distribution of the neuron's dendritic and axonal fields is a crucial step, for the ultimate understanding of the functional role of a neuron (Miles et al., 1996; DeFelipe, 2002). Therefore, it is fair to assume that two neurons with a nearly identical structural and immunohistochemical properties but associated with dissimilar bulbar areas and hence, with different fiber and cellular domains, should assume different functional roles. The top panels of Figure 6 reproduce three interneurons that, on the sole basis of their somato-dendritic structure, might initially be classed in the same group (i.e., deep, short axon neurons). Indeed, all of them possess a spindle-or pear-shaped soma and give rise to various dendrites with few, or devoid of spines. However, if further dendritic and axonal criteria (i.e., topography, shape and dimensions) are added to the somato-dendritic picture, the former grouping would be too general or even simplistic. With these supporting arguments, we decided to classifying these neurons as separate entities. In précis, although the short axon-interstitial neurons of the bulbi, the main-accessory cell (see Pressler and Strowbridge, 2006; Larriva-Sahd, 2008), and the medullary interneuron (Paredes and Larriva-Sahd, 2010), and the interneuron described here in the aAOB, share somato-dendritic features between them, their association with distinct fiber systems and putative synaptic targets justify to classify them as separate entities.

\section{ACKNOWLEDGMENTS}

This work is dedicated to the memory of Professor Edward (Ted) G. Jones. supported by a grant from PAPIT: IN206511. The author thanks Gema Martínez Cabrera for her careful technical help and Dr. Dorothy Pless for her effective revision of the manuscript.

in Cerebral Cortex, Vol. 1, eds A. Peters and E. G. Jones (New York, NY: Plenum Press), 123-200.

Fuss, S. H., Omura, M., and Mombaerts, P. (2005). The Grueneberg ganglion of the mouse projects axons to glomeruli in the olfactory bulb. Eur. J. Neurosci. 22, 2649-2654.

Greer, C. A., Stewart, W. B., Teicher, M. H., and Shepherd, G. M. (1982). Functional development of the olfactory bulb and a unique glomerular complex in the neonatal rat. J. Neurosci. 2, 1744-1759.

Grueneberg, H. (1973). A ganglion probably belonging to the $\mathrm{N}$.
Terminalis system in the nasal mucosa of the mouse. Z. Anat. Entwicklungsgesch. 140, 39-52.

Hirata, Y. (1964). Some observations on the fine structure of the synapses in the olfactory bulb of the mouse, with particular reference to the atypical synaptic configuration. Arch. Histol. Jpn. 24, 293-302.

Honda, N., Sakamoto, H., Inamura, K., and Kashiwayanagi, M. (2008). Changes in Fos expression in the accessory olfactory bulb of sexually experienced male rats after exposure to female urinary pheromones. Eur. J. Neurosci. 27, 1980-1988. 
Kosaka, T., and Kosaka, K. (2011). "Interneurons" in the olfactory bulb revisited. Neurosci. Res. 69, 93-99.

Kosaka, T., and Kosaka, K. (2007). Heterogeneity of nitric oxide syntetase-containing neurons in the mouse olfactory bulb. Neurosci. Res. $57,165-178$.

Larriva-Sahd, J. (2004). Juxtacapsular nucleus of the stria terminalis of the adult rat: extrinsic inputs, cell types, and neuronal modules: a combined Golgi and electron microscopic study. J. Comp. Neurol. 475, 220-237.

Larriva-Sahd, J. (2006). A histological and cytological study of the bed nuclei of the stria terminalis of the adult rat. II. Oval nucleus: extrinsic inputs, cell types, and neuronal modules. J. Comp. Neurol. 497, 772-807.

Larriva-Sahd, J. (2010). Chandelier and interfascicular neurons in the adult mouse piriform cortex. Front. Neuroanatomy 4:148. doi: 10.3389/ fnana.2010.00148

Larriva-Sahd, J. (2008). The accessory olfactory bulb in the adult rat: a cytological study of its cell types, neuropil, neuronal modules, and interactions with the main olfactory system. J. Comp. Neurol. 510, 309-350.

Lledo, P. M., Merkle, F. T., and AlvarezBuylla, A. (2008). Origin and function of olfactory bulb interneuron diversity. Cell 31, 392-400.

Lohman, A. H. M., and Mentink, G. M. (1969). The lateral olfactory tract and the anterior commissure, and the cells of the olfactory bulb. Brain Res. 12, 396-413.

Lohman, A. H. M. (1963). The anterior olfactory lobe of the guinea pig. Acta. Anat. 45, 9-109.

Lorente de Nó, R. (1938). Analysis of the activity of the chains of internuncial neurons. J. Neurophysiol. 1, 207-244.

Lorente de Nó, R. (1949). “Cerebral cortex: architecture, intracortical connections, motor projections," in Physiology of the Nervous System, ed J. F. Fulton (New York, NY: Oxford University Press), 288-312.

López-Mascaraque, L., De Carlos, J. A., and Valverde, F. (1986). Structure of the olfactory bulb of the hedgehog (Erniaceus europaeus): description of cell types in the granule layer. J. Comp. Neurol. 253, 135-152.

Macrides, F., and Davis, B. J. (1983). "The olfactory bulb," in Chemical Neuroanatomy, ed P. C. Emson (New York, NY: Raven Press), 391-426.

Martel, K. L., and Baum, M. (2009). A centrifugal pathway to the mouse accessory olfactory bulb from the medial amygdale conveys genderspecific volatile pheromonal signals. Eur. J. Neurosci. 29, 368-376.

Miles, R., Toth, K., Gulyas, A. I., Hajos, N., and Freund, T. F. (1996). Differences between somatic and dendritic inhibition in the hippocampus. Neuron 16, 815-823.

Paredes, G., and Larriva-Sahd, J. (2010). Medullary neurons in the core white matter of the olfactory bulb: a new cell type. Cell Tissue Res. 339, 281-295.

Pereno, G. L., Balaszczuk, V., and Beltramino, C. A. (2011). Detection of conspecific pheromones elicit fos expression in GABA and calciumbinding cells of the rat vomeronasal system-medial extended amygdala. J. Physiol. Biochem. 67, 71-85.

Pressler, R. T., and Strowbridge, B. W. (2006). Blanes cell mediate persistent feedforward inhibition onto granule cells in the olfactory bulb. Neuron 49, 889-904.

Ramón y Cajal, S. (1904). "Corteza Olfativa," in Textura del Sistema Nervioso Central del Hombre $y$ los Vertebrados Vol. 2, Imprenta y Librería Nicolás Moya, España.

Ring, G., Mezza, R. C., and Schwob, L. E. (1997). Immunohistochemical identification of discrete subsets of rat olfactory neurons and the glomeruli that they innervate. $J$. Comp. Neurol. 388, 415-434.

Senba, E., Simmons, D. M., and Swanson, L. W. (1990). Localization of neuropeptide precursorsynthesizing neurons in the rat olfactory bulb: a hybridization histochemical study. Neuroscience 38, 629-641.

Shinoda, K. Y., Shiotani, Y., and Osawa, Y. (1989). "Necklace olfactory glomeruli" form unique components of the rat primary olfactory system. J. Comp. Neurol. 284, 362-373.

Stowers, L., and Logan, D. W. (2010) Olfactory mechanisms of sterotyped behavior: on the scent of specialized circuits. Curr. Opin. Neurobiol. 20 274-280.

Teicher, M. H., Stewart, W. B., Kauer, J. S., and Shepherd, G. (1980). Suckling pheromone stimulation of a modified glomerular region in the developing rat olfactory bulb revealed by the 2-deoxyglucose method. Brain Res. 194, 530-535.

Toida, K., Kosaka, K., Heizmann, C. W., and Kosaka, T. (1996) Electron microscopic serialsecrioning/reconstruction study of parvalbumin-containing neurons in the external plexiform layer of the rat olfactory bulb. Neuroscience 72 , 449-466.

Valverde, F., López-Mascaraque, L., and De Carlos, J. A. (1989). Structure of the nucleus olfactorius anterior of the hedgehog (Erinaceus europaeus). J. Comp. Neurol. 279, 581-600.

Valverde, F. (1965). Studies of the Pyriform Lobe. Cambridge, MA: Harvard University Press.

Xu, F., Schafer, M., Kida, I., Schafer, J., Liu, N., Rothman, D. L., Hyder, F., Restrepo, D., and Shepherd, G. M. (2005). Simultaneous activation of mouse main and accessory olfactory bulbs by odors and pheromones. J. Comp. Neurol. 489, 491-500.

Yan, Z., Tan, J., Qin, C., Lu, Y., Ding, C., and Luo, M. (2008). Precise circuitry links bilaterally symmetric olfactory maps. Neuron 58, 613-624.

Conflict of Interest Statement: The author declares that the research was conducted in the absence of any commercial or financial relationships that could be construed as a potential conflict of interest.

Received: 21 May 2012; paper pending published: 01 June 2012; accepted: 06 June 2012; published online: 27 June 2012.

Citation: Larriva-Sahd J (2012) Cytological organization of the alpha component of the anterior olfactory nucleus and olfactory limbus. Front. Neuroanat. 6:23. doi: 10.3389/fnana. 2012.00023

Copyright (c) 2012 Larriva-Sahd. This is an open-access article distributed under the terms of the Creative Commons Attribution Non Commercial License, which permits non-commercial use, distribution, and reproduction in other forums, provided the original authors and source are credited. 